\title{
Interplay between HIV-1 and Host Genetic Variation: A Snapshot into Its Impact on AIDS and Therapy Response
}

\author{
Raghavan Sampathkumar, ${ }^{1}$ Elnaz Shadabi, ${ }^{1}$ and Ma Luo ${ }^{1,2}$ \\ ${ }^{1}$ Department of Medical Microbiology, University of Manitoba, Winnipeg, MB, Canada R3E 0J9 \\ ${ }^{2}$ National Microbiology Laboratory, Public Health Agency of Canada, Winnipeg, MB, Canada R3E 3R2 \\ Correspondence should be addressed to Ma Luo, ma.luo@phac-aspc.gc.ca
}

Received 9 December 2011; Revised 26 February 2012; Accepted 11 March 2012

Academic Editor: Nicola Coppola

Copyright (c) 2012 Raghavan Sampathkumar et al. This is an open access article distributed under the Creative Commons Attribution License, which permits unrestricted use, distribution, and reproduction in any medium, provided the original work is properly cited.

\begin{abstract}
As of February 2012, 50 circulating recombinant forms (CRFs) have been reported for HIV-1 while one CRF for HIV-2. Also according to HIV sequence compendium 2011, the HIV sequence database is replete with 414,398 sequences. The fact that there are CRFs, which are an amalgamation of sequences derived from six or more subtypes (CRF27_cpx (cpx refers to complex) is a mosaic with sequences from 6 different subtypes besides an unclassified fragment), serves as a testimony to the continual divergent evolution of the virus with its approximate $1 \%$ per year rate of evolution, and this phenomena per se poses tremendous challenge for vaccine development against HIV/AIDS, a devastating disease that has killed 1.8 million patients in 2010. Here, we explore the interaction between HIV-1 and host genetic variation in the context of HIV/AIDS and antiretroviral therapy response.
\end{abstract}

\section{Introduction}

The evidence for HIV to be the causative agent of AIDS was documented way back in 1983, and, hitherto, the dreadful HIV remains unconquered [1]. As of 2010, 34 million people are living with HIV infections and 2.7 million people have been newly infected in that year alone [2]. This alarming statistics have accelerated much research into the biology of HIV, seeking clues on "Achilles heel" so as to curtail its spread and eventually to eradicate it.

\section{HIV-1 Origin and Diversity}

HIV-1 and HIV-2 cause AIDS, and HIV-1, with its tremendous diversity, outwits HIV-2 by its ability to inflict a more virulent form of the disease and has global distribution [3]. Both viruses originated in Africa, and viral zoonosis resulted in the rampant AIDS epidemic. Simian immunodeficiency virus (SIV) from chimpanzees ( $\left.\mathrm{SIV}_{\mathrm{CPZ}}\right)$ is closely related to HIV-1, while SIV from sooty mangabeys $\left(\right.$ SIV $\left._{S M}\right)$ forms the closest to HIV-2 $[4,5]$. HIV-1 viruses fall under three main phylogenetic lineages, namely, M (Main), O (outlier), and $\mathrm{N}$ (non-M/non-O), all considered to have originated from chimpanzees dwelling in the eastern equatorial forests of Cameroon, West Central Africa, with O group viruses through a gorilla intermediate [6-8]. SIV infected Pan troglodytes troglodytes $(\mathrm{Ptt})$ chimpanzees gave rise, through crossspecies transmission, to HIV-1 groups $\mathrm{M}$ and $\mathrm{N}$ viruses while SIV-infected gorillas (Gorilla gorilla; SIVgor), which themselves contracted infection originally from chimpanzees, gave rise to formation of group O HIV-1 viruses. Recently, a variant of HIV-1 group $\mathrm{O}$ virus has been detected-P group-which resembles more closely to SIVgor than O group virus, in individuals of Cameroon origin $[9,10]$. Studies have estimated the timing for origin of each lineage of HIV-HIV-1 group M, O, and N at 1931 (1915-1941), 1920 (1890-1940), and 1963 (1948-1977), respectively [1113]. HIV-2 viruses are considered to have originated around 1930s [13].

Group M HIV-1 viruses are further subdivided into nine major subtypes, namely, A-D, F-H, J, and K. Sub-subtypes have been reported for clade A (A1 and A2) and F (F1 and F2) viruses. Group $\mathrm{M}$ also includes circulating recombinant forms (CRFs). Figures 1(a) and 1(b) illustrate global distribution of HIV subtypes and most common CRFs, respectively. Circulating recombinant forms arise as a result of 


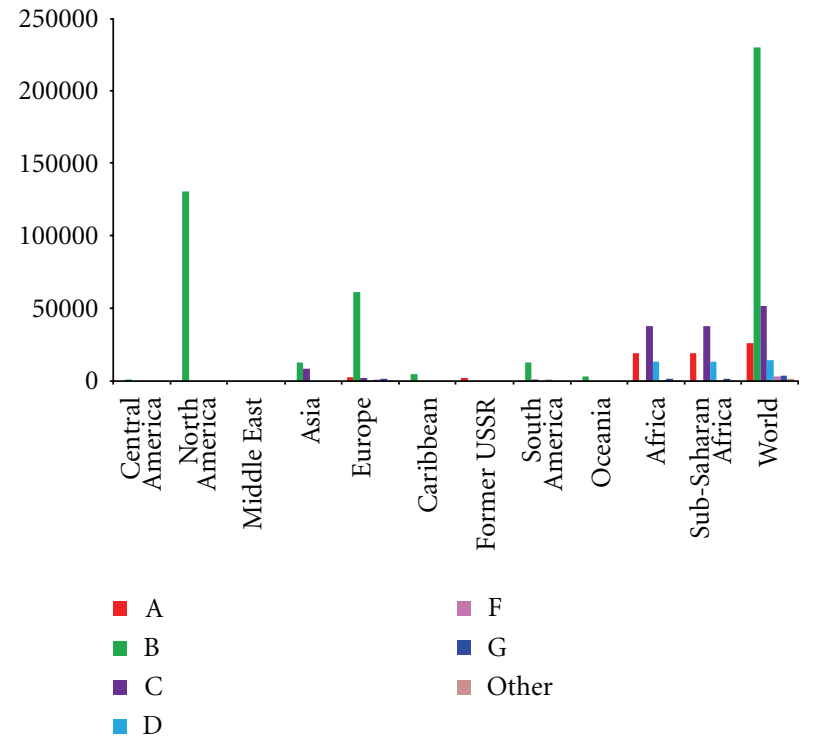

(a)

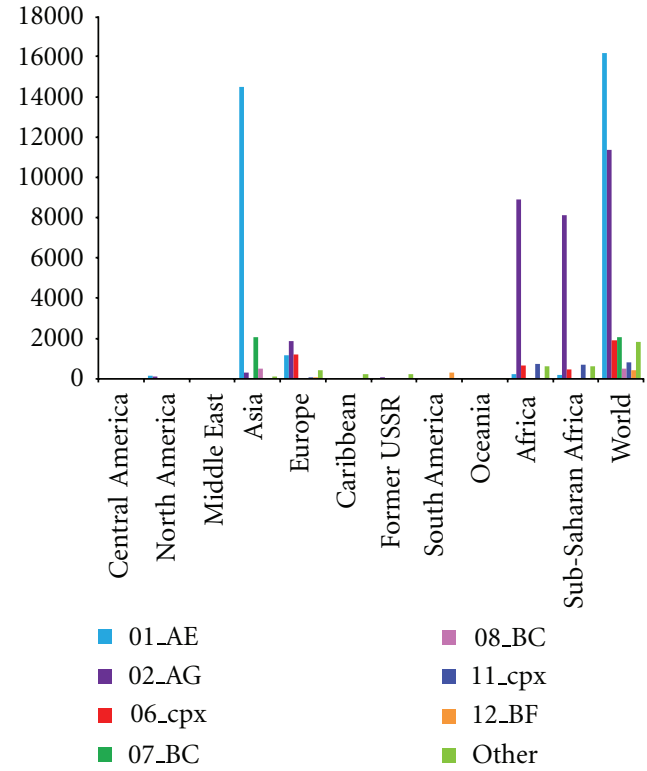

(b)

FIGURE 1: (a) Global distribution of HIV-1 (nonrecombinants) sequences. (b) Global distribution of recombinant HIV-1 sequences. Source: HIV databases [14].

recombination between any of the subtypes and/or CRFs leading to the formation of CRFs such as $\mathrm{AE}, \mathrm{AG}, \mathrm{AB}, \mathrm{DF}, \mathrm{BC}$, $\mathrm{CD}$, and other complex forms. Figure 2 provides a schematic representation of composition of $50 \mathrm{CRF}$ that have been identified hitherto [14]. The subtypes and CRFs attest to the genetic diversity of HIV-1. These M group viruses cause most of the HIV-1 infections, accounting for the current AIDS pandemic. Circulating recombinant forms account for about $10 \%$ of all HIV infections [8], and the proportion might increase in future. Different subtypes among HIV-1 viruses impact disease progression differently [15] and may also have differential sensitivity to antiretroviral therapy (ART) drugs [16]. Individuals infected with subtype D viruses are known to experience rapid disease progression [17], whereas those infected with subtype $\mathrm{C}$ undergo slow disease progression [18]. During the course of HIV-1 infection, strains that utilize coreceptor CXCR4, emerge during late stages of infection in contrast to CCR5 utilizing $M$ tropic strains that are seen during early stages of infection. The strains that use CXCR4 are known to exhibit cytopathic effect in vitro [19]. However, this observation might be an in vitro artifact since little cytopathic effects were noticed in vivo [20]. There is differential usage of CXCR4 coreceptor among subtype C and $D$ viruses, with subtype $C$ viruses rarely switching to CXCR4 usage and subtype D viruses utilizing CXCR4 receptor earlier and frequently, and this, alongwith other factors like genetic variation in long terminal repeat (LTR) promoter, might account for their varied impact on disease progression $[8,21-24]$. The promoter/enhancer activities of LTRs of subtype $C$ viruses were shown to be higher than that of other subtypes A, B, D, E, and G [23], and subtle differences in promoter activity of LTRs might affect HIV replication kinetics substantially $[24,25]$. The intrasubtype diversity is substantial among different subtypes of HIV-1. The protein sequence diversity among subtypes of HIV-1 group $\mathrm{M}$ viruses for Gag, Pol, and Env are reported to be $15 \%, 10 \%$, and $24 \%$, respectively [26]. Gag-30 position is phylogenetically important. The sequences of $\operatorname{SIV}_{\mathrm{CPZ}} P t t$, from which HIV-1 originated, are marked by presence of Met at Gag-30. In contrast, the ancestors of all the three HIV-1 groups $(\mathrm{M}, \mathrm{O}$, and $\mathrm{N})$ are marked by sequences that contain Arg at Gag-30, highlighting potential host-species-specific adaptation [27]. Understanding HIV evolution and the role that the host plays in mediating it and controlling infection will undoubtedly help to determine the effective approaches to combat HIV/AIDS.

\section{Degree of HIV-1 Variability}

HIV-1, with its RNA genome, demonstrates significant genetic diversity due its high mutation rate. It has diversified itself to such an extent, through its ability to form "cloud" of variants or quasispecies, that there is no single wild-type strain. In vitro data have shown that RNA viruses generate nonhomogeneous genetic clones that are closely related but genetically diverse, which are known as quasispecies. This phenomenon, which aids viruses to persist in their host, possibly causing disease, is observed in other RNA viruses such as hepatitis $C$ and influenza virus as well $[28,29]$. The reverse transcriptase (RT) of HIV-1, which lacks $3^{\prime}-5^{\prime}$ exonucleolytic proof-reading function, misincorporates 1 in 6900 and 1 in 5900 nucleotides polymerized on the RNA and DNA template, respectively, and hence accounts for larger proportion of mutations seen in HIV-1 [30]. It has been estimated that, after a single round of HIV-1 replication, under 


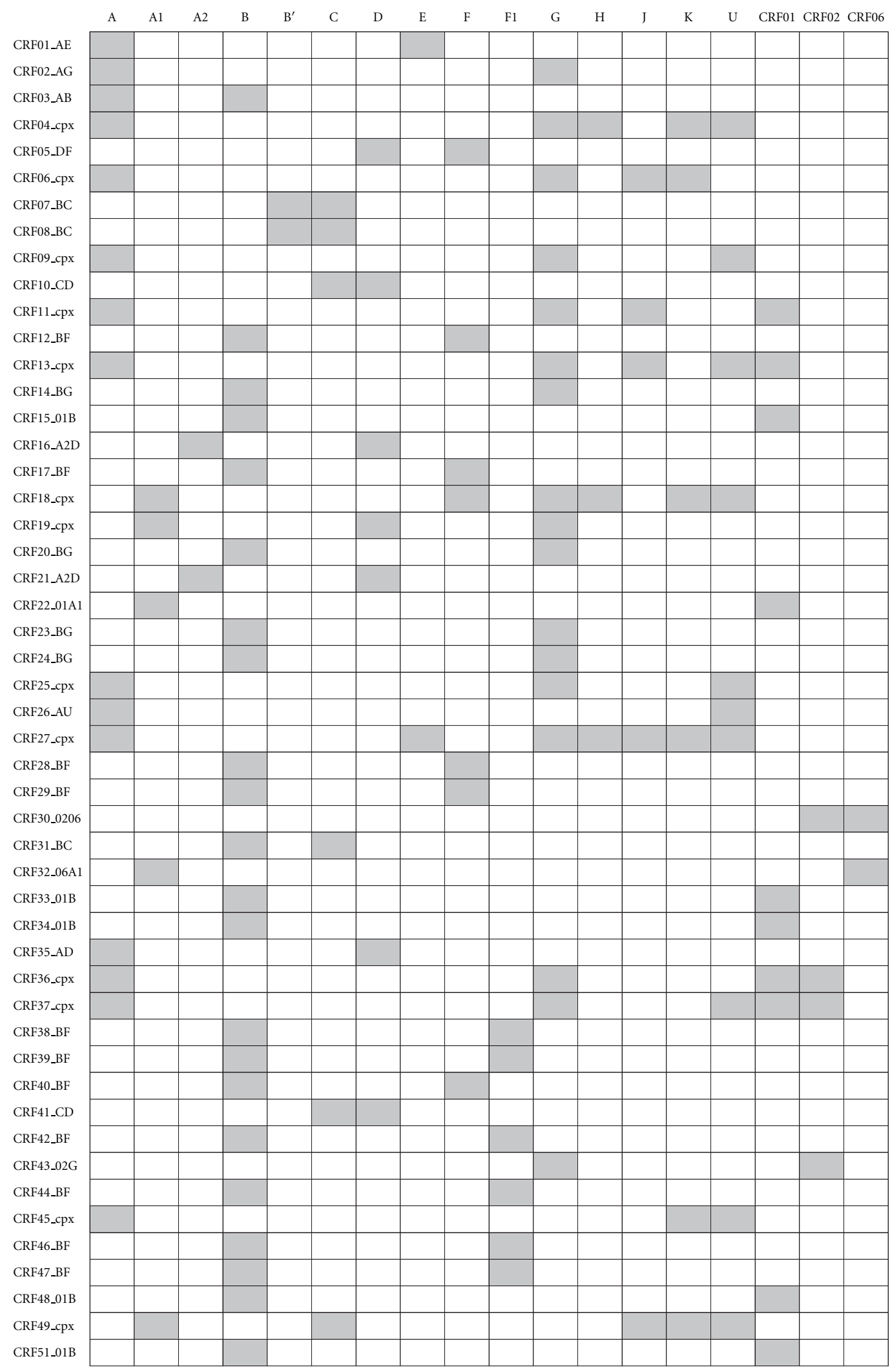

Note: U: unclassified

FIGURE 2: Schematic representation of composition of HIV-1 CRFs. 
the assumption of absence of selection pressure, the resulting progeny viruses will have substitution, frameshift and deletions at $24 \%, 4 \%$, and $2 \%$, respectively [31]. It is interesting to note that $80 \%$ of heterosexual-mediated HIV-1 infections are due to productive infection by a single HIV-1 virion [3234]. HIV-1 evolves at about $1 \%$ per year [35]. Given that HIV-1 faces selection pressures, a gamut of mutations has shaped its genome since its origin, which in turn, ensures its virulence at population level $[36,37]$, despite the fact that certain mutations in its conserved region impacts its fitness negatively [38]. Further, a recent study that utilized phylogenetic comparative approach revealed that viral genotype, as against the host genetic profile, largely determines the HIV set-point viral load and hence the virulence [39]. A schematic sketch of error-causing machinery involved in HIV-1 mutagenesis and a gamut of selection pressure acting on HIV-1 are provided in Figures 3(a) and 3(b), respectively.

3.1. Ultra-Deep Sequencing Reveals Vastness of HIV-1 Variability. With the emergence of new pyrosequencing technology, HIV-1 viral quasispecies are now more rapidly and accurately sequenced and analyzed. Mutation spectra of HIV-1 quasispecies are wide, and traditional sequencing methodologies are limited in their ability to capture minority variants [40]. Next generation sequencing (NGS) methodologies have made it possible to obtain high-throughput sequence data at an unprecedented pace and coverage (e.g., pyrosequencing using GS FLX+ system permit characterizing up to 1000 bp read length with $1,000,000$ reads per run at run time of 23 hours and consensus accuracy of 99.997\%) [41, 42] and are being employed to decipher HIV-1 evolutionary trajectories [34, 43]. Recently, Liang et al. [44] used 454 pyrosequencing technology and sanger clone-based sequencing to assess the genetic diversity of HIV-1 gag and it was determined that pyrosequencing detected almost four times more variation in gag than sanger sequencing. Ultra-deep sequence sets of HIV-1 allow for deciphering CTL escape variants that are not discernable with the sequences obtained through conventional sequencing strategies [34, 44]. While single genome amplication (SGA) is superior to standard genotyping method [45], ultra-deep sequencing methods offer highest sensitivity to date in relation to those conventional methods as it can detect minor viral variants that comprise lower than $1 \%$ of the population. This highest level of sensitivity by ultra-deep sequencing also allows for identifying low-abundance drug resistant variants [40], with potential to interfere with ART outcome. Not only NGS techniques are used to gain insights into the sequence of the viral genome with greater depth, it has also been recently utilized to examine viral diversity after therapy. For example, a study that used deep sequencing technology to examine escape mutations in the V3 loop of HIV-1 that arise as a result of selection by CCR 5 antagonist (vicriviroc, a drug that inhibits HIV-1 entry) therapy indicated significantly higher sequence heterogeneity [43]. Knowledge on nature of HIV-1 quasispecies gained through ultra-deep sequencing technologies can aid in progressing HIV research and managing HIV/ AIDS clinically better. Finally, with advanced whole genome sequencing technologies, the ability to correlate genome profile of HIV with that of patients could lead to comprehensive understanding of disease process and effective interventions.

\subsection{Factors Driving HIV-1 Variability}

(a) Inherent Property of the Reverse Transcriptase (RT) and Recombination. The generation of diverse variants in HIV-1 can be attributed mainly to its low-fidelity RT enzyme, leading to error-prone reverse transcription [30]. RT also accounts for genomic heterogeneity in progeny viruses through its role in recombination. Besides RT, which accounts for larger proportion of mutations observed in HIV-1, the host RNA pol II involved in transcription of proviral DNA can also contribute to mutations, albeit minimally. A study has indicated contribution of cellular RNA pol II to be less than $3 \%$ of retroviral frame-shift mutations [46].

HIV-1, with documented dual and triple infections in patients $[47,48]$, can substantially drive production of viral quasispecies that are endowed with superior fitness through the process of genetic recombination, a time-tested evolutionary strategy to thrive in a changing environment. With an average of $1.38 \times 10^{-4}$ recombination events/adjacent sites/generation in vivo [49], HIV-1 ensures its ability to enrich both diversity and fitness. In HIV-1, recombination in genomic regions with high selection pressure, either in the form of host immune response or ART drugs, could lead to selection of more fit genomes, while, in regions under negligible selection, recombination can enhance diversity [50]. HIV-1-infected commercial sex workers in Nairobi, Kenya, were shown to harbor high proportion of recombinant HIV1 viruses [51, 52]. Recombinants between highly similar HIV-1 strains are formed at highest frequencies while that between very distant HIV-1 strains occur at very low frequencies [53]. Genetic recombination between HIV-1 and HIV-2 is also a potential possibility [54].

(b) Swift Turnover Rates of HIV-1 In Vivo. HIV-1 virions are produced and cleared at extremely rapid pace. HIV-1 turnover is high at $10^{11}$ virions and $10^{8}$ infected cells per day [45]. Studies have estimated that free HIV-1 viral particles have an half-life of less than 6 hours, while the productively infected cells possess an half-life of about 1 day [55]. This rapid turnover has been considered as the major factor underlying pathogenesis of HIV/AIDS, wherein there is greater destruction of $\mathrm{CD} 4^{+} \mathrm{T}$ helper lymphocytes.

(c) Drugs of ART Drive Changes in HIV Genetic Makeup. Antiretroviral drugs as well as associated drug resistance mutations could influence in vivo HIV-1 mutation rates. The drug $3^{\prime}$-azido- $3^{\prime}$-deoxythymidine (AZT) can enhance HIV-1 mutation rate by a factor of seven per round of replication, and HIV-1 variants harbouring AZT resistant RT can incur higher mutation rate as much as threefold relative to wildtype RT bearing HIV-1 [56]. The V106A is a nevirapine (nonnucleoside RT inhibitor) resistance mutation that has been consistently shown to affect viral fitness severely [57]. Mutations associated with HIV-1 drug resistance could be 


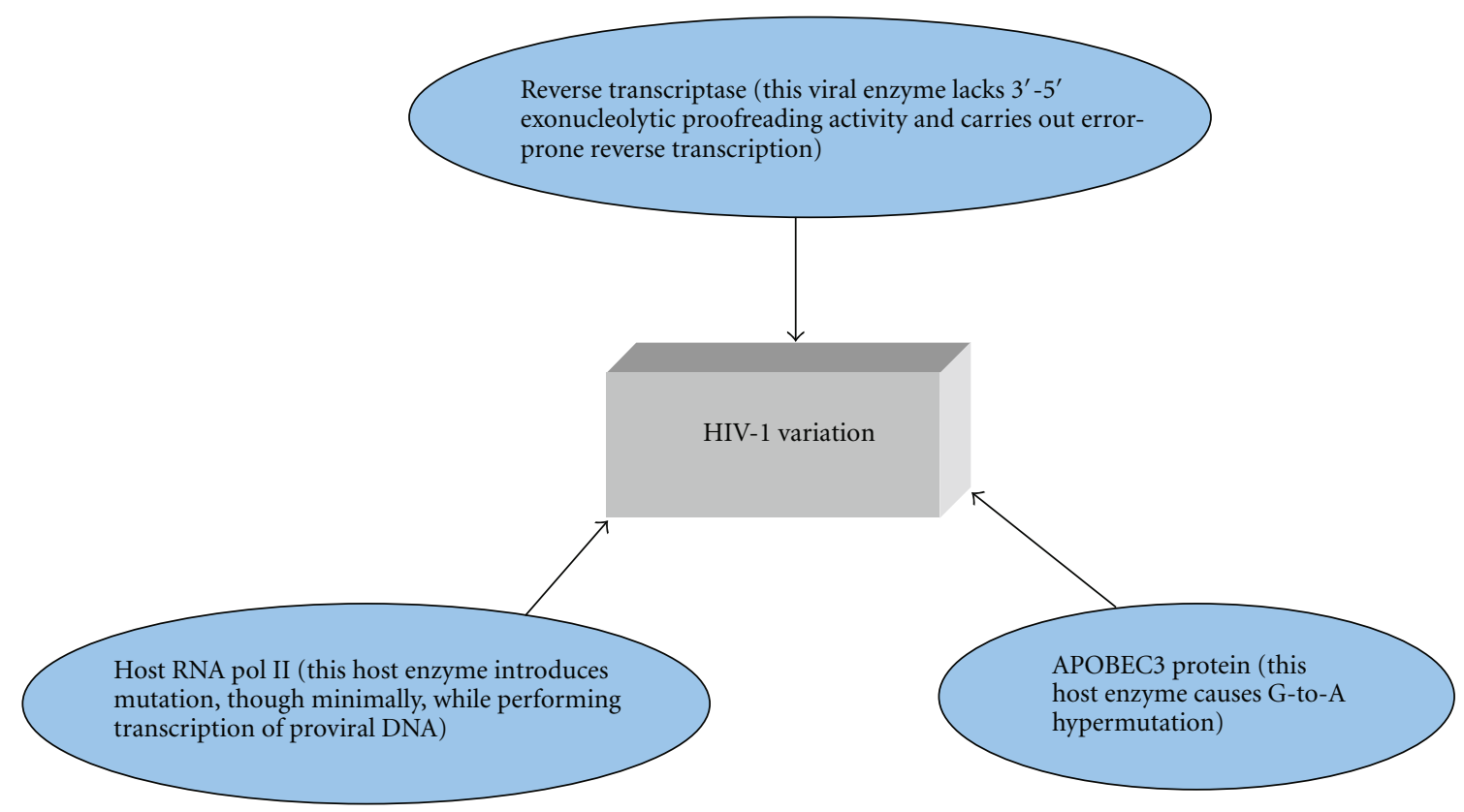

(a)

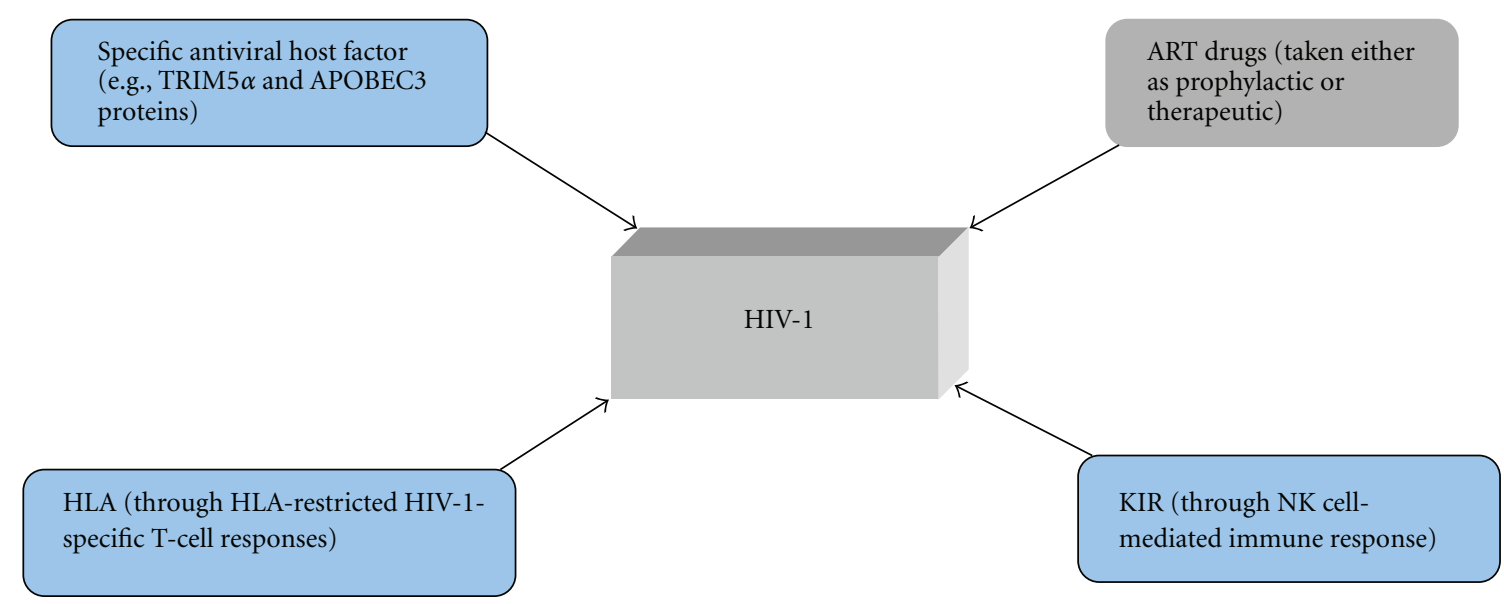

(b)

FIGURE 3: (a) Error-causing machinery involved in HIV-1 mutagenesis. (b) A schematic sketch of selection pressures acting on HIV-1. Note: ART drugs block is shown in grey colour to differentiate from others, as such drugs exert influence over HIV-1 indirectly in patients undergoing ART.

present in drug-naïve patients at low frequencies, often interfering with outcome of ART [58]. Metzner et al. [59] have reported occurrence of M184V (RT) and L90M (protease) mutations as minority populations in patients undergoing structured treatment interruptions. A comprehensive list of ART drug-associated mutations is being maintained in Stanford HIV Drug Resistance Database [60]. Further discussion on ART drugs is covered in Section 6.

(d) Selective Immune Pressures from Host. There is heterogeneity in disease progression among HIV-1-infected patients. Host genetic variants have been shown to account for at least $15 \%$ of the observed differences in disease progression
[61]. Human leukocyte antigen (HLA) system, residing in the sixth chromosome, is the most polymorphic loci in human genome and this extensive polymorphism is the result of evolving with millions of pathogens that the human species has faced throughout its existence [62,63]. This elaborate polymorphic nature of HLA alleles enables them to recognize various protein fragments of pathogens and present to T cells for generation of appropriate immune responses. Among these host genetic factors, HLA class I molecules, which present peptides to cytotoxic $\mathrm{T}$ cells, have been shown to exert profound influence over controlling the HIV-1. The protective alleles, HLA-B*57, $-B^{*} 27$, and $-B^{*} 51$, through presentation of highly conserved HIV-1 epitopes to cytotoxic $\mathrm{T}$ lymphocytes (CTL) and subsequent immunodominant 
immune response, drive formation of specific CTL escape mutants, that are compromised in their replicative fitness [64-68]. These CTL escape mutants, depending on nature of HLA-mediated immune pressure from subsequent hosts in the transmission chain, may get either fixed in the population or get reverted to their wild type form [38,69]. Selection pressure exerted by host on HIV-1 is discussed further under the subsequent Section 4.

\section{Host Genetic Factors Influence HIV-1 Evolution}

HIV-1 adapts to host immune pressure, and this is revealed through studies of positively selected amino acid changes in different proteins of the virus [70-74]. An immunoinformatic analysis that looked at envelope sequences across clades from varied geographical regions has indicated differences in frequency of positive selection (PS) sites, suggesting that viral clades prevalent in various geographically distinct parts of the globe evolve in response to the characteristic immunogenetic profile of the host population [70]. Evolutionary pathways of HIV-1 appear to be vast with occurrence of positive selection sites not only in epitopes of $\mathrm{CD}^{+}$and $\mathrm{CD}^{+} \mathrm{T}$ cells and antibodies, wherein HLA impacts profoundly, but also in other regions which are likely to suffer selection pressure via effectors of innate arm of the immune system such as KIR and HIV restriction factors TRIM $5 \alpha$, APOBEC3G [75]. In contrast, HIV-2 that causes less severe form of disease face significant negative selection pressure [76].

Several AIDS restriction genes have been identified [77, 78]. Among these HLA, killer-cell immunoglobulin-like receptors (KIRs), chemokine receptors and intrinsic antiviral factors like TRIM $5 \alpha$, APOBEC3 are known to exert substantial influence over HIV/AIDS and affect HIV-1 evolution. TRIM $5 \alpha$, for example, has the ability to recognize the capsid protein of the incoming virus and disassembling it upon entry [79]. APOBEC3 proteins are another group of host restriction factors that play a role in reducing viral infection, including HIV-1 [80]. These host proteins are cytidine deaminases that catalyze the deamination of cytidine to uridine, which results in guanosine to adenosine hypermutation in the concerned opposite strand, favouring inactivation of the virus $[79,81]$. HIV-1 negates the antiviral effects of APOBEC3G (A3G) through its Vif (viral infectivity factor). Viral infectivity factor promotes proteosomal degradation of A3G in an incomplete fashion, as a result of which there is generation of hypermutated viral population that could still survive, aiding HIV-1 evolution and possibly favouring emergence of drug resistant forms [82]. Fourati et al. [83] showed that HIV patients exhibiting virological treatment failure often possessed $\mathrm{K} 22 \mathrm{H}$ point mutation in Vif, which resulted in inability of Vif to counteract APOBEC3 proteins, ultimately leading to G-to-A hypermutation in HIV. Several other studies have also demonstrated role of APOBEC3 proteins in HIV-1 evolution [84-87]. Recently, study by Norman et al. [88] indicated that HIV-1 also employs viral protein $\mathrm{R}$ (Vpr) to negate A3G antiviral properties by diminishing the incorporation of uridines in the deamination process. Interestingly, this act by Vpr results in favour of host as DNA damage response pathway got triggered and NK cellactivating ligands got expressed, making the virus vulnerable to attack by NK cells [88]. Human tetherin also acts to prevent the spread of HIV-1 infection to other cells. Tetherin, a cell surface host protein, is able to trap virions that are being released from the surface of the infected cell $[79,89]$. Differential adaptation of HIV-1 viruses to antiviral activity of tetherin has been recently confirmed. Yang et al. [90] demonstrated that while Vpu of both group M and N HIV-1 viruses had activity against human tetherin, Vpu and Nef from group $\mathrm{O}$ and $\mathrm{P}$ viruses lacked such anti-tetherin activity. A very recent study by Liu et al. [91] reported identification of 114 intrinsic host factors with significant ability to inhibit HIV-1 infection and this illustrates the tremendous pressure HIV-1 is subjected to, upon entry into its host. It could be inferred that various host genetic factors might additively contribute to controlling the virus. The complex HIV-1 host interactions are being dissected using genomewide and large-scale strategies to map virus-host interactions comprehensively [92].

4.1. HLA Leaves Footprints on HIV-1. The impact of HLA diversity on HIV evolution has been documented in several studies. Different HLA alleles have been shown to be associated with different rates of HIV disease progression. For example, patients who possess HLA-B*27 and -B*57 alleles normally have low viral loads and progress to AIDS at a much slower rate, while those possessing HLA-B* 35 progress to AIDS defining illnesses rapidly [64]. HIV-1 is under pressure from HLA-mediated CTL responses quite early in the infection as CTL escape mutations have been shown to arise as early as 14 days of postinfection [93]. CTL epitopes, are reported to be more conserved compared to $\mathrm{CD} 4^{+} \mathrm{T}$ helper and monoclonal antibody epitopes and this conservation of CTL epitopes has been suggested as a host strategy to constrain HIV-1 adaptation [94]. Evidence of HLA footprint on HIV-1 genome is demonstrated by studies that have investigated the mutation profile of original infecting HIV1 strains. Leslie et al. [95] analyzed the mutation of clade B and C HIV-1 in patients with HLA-B*57/58:01 allele, which are associated with slow progression to AIDS. It was observed that positively selected amino acids had accumulated and, once transmitted to HLA-B* 57/B* 58:01 negative individuals, the virus reverted back to its wild-type form [95]. This illustrates the ability of HLA alleles to drive the necessary mutation in HIV, as part of controlling the infection. In another study, the carriage of HLA-B*57 allele in patients infected with HIV-1 and its impact on viral control was assessed. It was demonstrated that individuals expressing the HLA-B* 57 allele controlled viremia without therapy at levels $<5000$ copies/mL of virus for upto 29 months, and a stronger and broader response was generated by HLA-B* 57 allele than other HLA class I alleles [96]. A Swiss HIV cohort study, that reported similar transcriptome profile of $\mathrm{CD}^{+}$and $\mathrm{CD}^{+} \mathrm{T}$ cells among rapid progressors and pathogenic SIVinfected rhesus macaques, also found underrepresentation 
of protective alleles and overrepresentation of risk alleles at HLA loci in rapid progressors [97]. HLA selection pressure on HIV-1 is so fine-tuned that micropolymorphism seen among subtypes of a particular allele could exert differential pressure on virus. This phenomenon has been recently demonstrated for the HLA-B*57 alleles [98]. The support for extensive HLA associated selection in HIV-1 is also evident in the recent study by Dong et al. [99], wherein they followed a narrow-source HIV-1 outbreak, that occurred through a plasma donation scheme in a Chinese village and found 24$56 \%$ of the polymorphic sites across Gag, reverse transcriptase, integrase, and Nef had HLA footprints. A comprehensive genomewide association analysis has revealed that amino acids at positions 67, 70, and 97 in HLA-B play a major role in determining HIV-1 control, given their involvement in peptide binding within the peptide binding groove [100].

HLA-B loci, the most rapidly evolving class I region, contains alleles that exert strong selection pressure over HIV-1 through their allele-restricted $\mathrm{CD} 8^{+} \mathrm{T}$ cell responses and contributes to shaping of HIV-1 evolution [101, 102]. HLA-B might predominantly shape HIV and vice versa, a coevolution scenario $[67,101]$ as exemplified by Red Queen Hypothesis [103]. Also rapid selection for HLA alleles that protect against HIV-1 infection has been found to correlate significantly with declining incidence of HIV-1 in an East African sex worker cohort of Kenya, which suggests that natural selection might eventually play a vital role in containing the HIV-1 epidemic [104]. It may be plausible that mutome of HIV and human is being shaped by each other in a very delicate dynamic process of virus-human partnership.

Intrinsic and adaptive immunity might work synergistically to contain HIV-1. This can be inferred from the studies that have dissected role of HLA and KIR compound genotypes over HIV disease progression [105]. Further, recently CTL escape mutations in Gag have been shown to enhance sensitivity of HIV-1 to TRIM $5 \alpha$ [106]. It is plausible that HIV-1 could suffer a double whammy attack-one, fitness cost due to mutation in a highly conserved region and, second, increased vulnerability to attack from TRIM $5 \alpha$. In order to survive host immune pressure, which is predominantly dictated by HLA, HIV mutates at specific epitopic region and this escape variant to survive further without compromising its fitness might undergo compensatory mutations in regions away from the concerned epitope. Though HIV-1 mutates rapidly as a stochastic process, its mutational strategies are relatively predictable. The studies employing HIV-1-infected identical twins suggested the presence of a relatively narrow window period in HIV infection, wherein the immune responses, viral evolution as well as disease progression are somewhat reproducible and hence predictable [107-109]. Moreover, recently Dahirel et al. [110] have elegantly carried out coordinate linkage analysis employing a physics concept to highlight multidimensionally constrained regions of HIV-1 proteome. They have identified HIV sectors that is, distinct sets of amino acids whose mutations are collectively coordinated and indicated that among the five sectors of Gag, sector 3, which plays vital role in assemblage of multiprotein structures for formation of HIV-1 capsid, is the most immunologically vulnerable multidimensionally constrained and also is the sector most targeted by elite controllers of HIV1, who harbour protective HLA alleles. These studies bear potential clues for designing successful anti-HIV immunogens. While role of HLA class I alleles in attenuating HIV- 1 is vastly studied and supported by several findings, part played by HLA class II alleles has been scarcely investigated [64, $111,112]$. A recent study that investigated the correlation between HLA class II alleles and in vitro replication capacities of recombinant viruses encoding Gag-protease from HIV-1 subtype $\mathrm{C}$ infected chronic patients failed to detect any association of alleles with lower fitness [113]. However, earlier studies have demonstrated potential role of HLA class II alleles in exerting selection pressure on HIV-1 [114, 115]. More studies are warranted, given the reported significant genetic associations of alleles belonging to HLA-DR, -DQ, and -DP loci with HIV infection and disease [64, 111, 116120], to delineate degree of immune pressure exerted by different HLA class II alleles, the players in generating the essential $\mathrm{T}$ helper cell responses. T-cell-based vaccine strategies that could address HIV-1 diversity issues better are being tested $[121,122]$.

4.2. KIR Footprints on HIV-1. Killer-cell immunoglobulinlike receptor (KIR) encoding genes are located on chromosome 19, and their major role is to control the activation or inhibition of Natural Killer (NK) cells, which belong to the innate arm of the immune system. KIRs are quite polymorphic, and thus they are able to generate a diverse response to a variety of pathogens. KIRs mediate their effects using HLA molecules as ligands [123, 124].

HIV-1, like other viruses, down-regulate HLA class I molecules, specifically HLA-A and -B, and hence escapes from those HLA-mediated CTL effectors. However, in order to escape attack by NK cells, which destroys target cells lacking expression of HLA class I molecules, HIV-1 avoids downregulating KIR-interacting HLA-C or the nonclassical HLA-E molecules [125]. KIRs are known to impact HIV-1 disease outcome both independently and synergistically through its interaction with HLA ligands [126, 127]. A recent study has demonstrated role of copy number variation in KIR genes in influencing HIV-1 control [128]. Alter et al. [129] have shown that HIV-1 evades NK cell-mediated immune response by selecting for viral variants that modulate recognition of infected cells by KIR to their advantage. Specifically they identified 22 KIR-associated polymorphisms in HIV-1 from a cohort of 91 untreated chronically HIV-1infected patients. HIV-1 viruses with Vpu $(71 \mathrm{M} / 74 \mathrm{H})$ (Env (17 W/20 M)), Gag (138I), and Nef (9 K) were found to be significantly enriched in individuals possessing KIR2DL2, and these KIR footprints enhanced the binding of inhibitory KIR to infected cells, due to which inhibition of NK cell function ensues and HIV-1 escapes attack [129].

\section{Problems Posed by HIV-1 Diversity}

5.1. Search for a Broadly Cross-Reactive Anti-HIV Neutralizing Antibody. HIV-1 diversity is one among several challenges that needs to be addressed while attempting to design an 
effective anti-HIV vaccine. Generating broadly neutralizing antibodies (bnAbs) that can effectively inactivate or neutralize HIV variants remains elusive [130]. Broadly neutralizing antibodies are rare and undetectable in most HIV-1-infected individuals. Several hypotheses exist that attempt to explain the rarity of bnAbs. For example, one reason that has been proposed is that highly immunogenic epitopes may trigger nonneutralizing antibodies instead of activating required specific responses [131, 132]. However, nonneutralizing antibodies could be functional against HIV-1, as observed in study subjects of RV144 Trial [133], and have potential to mediate protection against HIV-1. Studies have also shown that antibodies sometimes select for escape mutations $[134,135]$. There are four regions of HIV-1 Env that could serve as targets for bnAbs: gp120 CD40 binding site, quaternary V2/V3 loop epitopes, gp41 Membrane proximal external region (MPER), and Env carbohydrates [132]. Human immunoglobulin, VRC01, is capable of neutralizing $90 \%$ of the HIV-1 isolates [136]. Recent studies have delineated both evolutionary course and nature of VRC01-like antibodies $[137,138]$, and this knowledge has opened up new avenues for strategies to attack HIV-1 better.

5.2. Correlates of Protection Obscured by HIV-1 Evolution. Certain host genotypes known to be favourable prior to ART might turn out to exert a detrimental or neutral effect upon initiation of treatment. This intriguing observation is being reported frequently, and yet the mechanism underlying the association is unclear. Rauch et al. [139] reported that Bw4 homozygosity, associated with protection in untreated patients, predicted impaired CD4 T-cell recovery upon commencement of combination ART. Another study revealed strong association of HLA-B* $57: 01$ and $-B^{*} 58: 01$, both exhibiting Bw4 motifs, with failure to control HIV replication following HAART initiation [140]. While HAART exhibits the potential to suppress HIV replication profoundly irrespective of the genotype of the individual, documented association of specific highly protective alleles with differential outcome over treatment may have an unidentified functional immunological basis and warrants extensive investigation. Antiretroviral therapy-induced selection pressure on pol could lead to generation of HIV-1 quasispecies with significant changes in epitope profile, including loss of protective epitopes. Furthermore, HLA-KIR interaction might contribute to outcome of ART $[139,140]$ and may explain the conundrum of what is good before ART is not so after ART.

HLA-B* 51 has been associated with protection against HIV-1 in Asian population [67, 68]. This allele has been able to confer a multilayered defence against HIV/AIDS through presentation of highly conserved immunodominant epitopes in Gag region, that rarely undergo mutation, and, if at all gets mutated, it is only at the cost of fitness. However, it has been noted that, over a period of time, at population level, the circulating viruses, as they evolve, tend to lose the epitopes targeted by the protective alleles such as HLA-B*51 [67, $68,141]$, such that documented protective association is obscured and these evolutionary strategies by which HIV changes its genomic/proteomic landscape to stay ahead, pose tremendous challenge for scientists as they search for true correlates of protection against HIV/AIDS and venture into developing a stable and effective intervention-prophylactic/ therapeutic vaccine $[142,143]$. Interestingly, a mathematical modeling study has predicted that the rate of generation of escape mutants and the transmission of escape mutants may have only a weak impact on the epidemic outcome over the first 25 years after the introduction of a nonsterilizing antiHIV vaccine [144]. However, search for a sterilizing vaccine for HIV/AIDS, a holy grail, remains vital aim in fight against HIV [145].

Characterizing immunological profile in both elite controllers and HIV-exposed seronegatives could lead to better understanding of correlates of protection [143, 146151]. Additionally, understanding immunobiological basis of benign nature of disease induced by HIV-2 can provide clues into virus-host interaction and aid in tackling HIV-1. Expanding HIV-1 diversity might pose problems at diagnostic level given its impact on viral load testing assays [152].

\section{Scope of ART in HIV-1 Control}

According to UNAIDS world AIDS day report 2011, at least 6.6 million people in low- and middle-income countries are receiving HIV treatment and this has resulted in prevention of 2.5 million AIDS deaths since 1995 [2]. Also ART prevents infection, as it reduces viral load and infectiousness of an infected individual [153]. While this is an encouraging sign towards combating the HIV/AIDS epidemic, it is to be emphasized that current drugs in the prescribed regimen are unable to attack and eradicate the viruses hiding in reservoirs such as seminal vesicles [154] and tissue macrophages of HIV infected patients [155]. Given the evidences that suggest continual on-going replication of HIV-1 in such reservoirs $[156,157]$, it is plausible that quasispecies that are immune to current combination ART drugs can emerge upon treatment interruption. HIV-1 occupies variety of anatomic compartments such as central nervous system (CNS), gut-associated lymphoid tissue (GALT), and genitourinary tract $[158,159]$. The CNS, endowed with blood-brain-barrier, is a pharmacologically "privileged" site, and the virus inside CNS thus gets shielded from attack by some ART drugs [159-161]. Genotypic diversity of HIV-1 is not uniform across different compartments [162]. This can be inferred by the fact that majority variant seen in blood is not always so in semen [163, 164]. Further, env sequences from blood and male genital tract compartments differ [165]. Venturi et al. [166] have observed different drug resistance mutation profile between HIV-1 isolates from cerebrospinal fluid and plasma in patients under nonsuppressive ART drug regimens. Indeed selective drug pressure has been shown to result in multiple drug-resistant HIV-1 quasispecies [167]. Viral rebound in patients who cease to continue with the ART is an added concern [168].

A recent study that evaluated the correlation of preexisting drug-resistant HIV-1 minority variants with risk of firstline nonnucleoside reverse transcriptase inhibitor (NNRTI) 
based antiretroviral virologic failure, by reviewing 10 different studies, has suggested significant association of lowfrequency drug resistance mutations with a dose-dependent increased risk of failure to control the virus [169]. Another cause for concern is the differential persistence of transmitted HIV-1 drug resistance mutation classes as reported by Jain et al. [170], wherein they indicated long-term persistence of NNRTI and protease inhibitor mutations which might facilitate person-to-person propagation. Adherence to drug regimen among HIV-1 patients is threatened by the fact that certain prescribed combination ART drugs could induce unfavourable side effects among patients with specific genotypes. For instance, hypersensitivity reactions (HSRs) are seen in HLA-B* 57 : 01 positive HIV-1 patients receiving Abacavir $(\mathrm{ABC})$, an nucleoside reverse transcriptase inhibitor (NRTI) drug [171]. While there are similar effects documented for other ART drugs [172], the association of ABC with HSR in HLA-B* 57:01 patients is robust enough that screening for this allele has been made routine prior to prescription of combination ART regimen containing $\mathrm{ABC}$ [173]. More insights into pathophysiology of drug-induced HSR in HIV patients can ensure case-specific recommendation of combination ART drugs, averting compliance issues and emergence of drug resistant viral population. He et al. [174], by conducting a 7-year follow-up study on 437 HIVinfected Chinese patients undergoing HAART, suggested that two NRTIs and one NNRTI regimens could persistently suppress HIV viremia and enhance $\mathrm{CD} 4^{+} \mathrm{T}$-cell population with good safety and tolerance. The study also reported 19.2\% of the participants changed to other first-line drug due to drug-related side effects and $10.2 \%$ switched to second-line regimens because of viral resistance. As UNAIDS and WHO advocate Treatment 2.0 [175], many such prospective studies analyzing outcome of HAART regimens are essential and antiretroviral pharmacovigilance [176] will attain greater importance.

HIV drug resistance could be either acquired or transmitted. According to recent initial survey conducted in lowand middle-income countries, WHO has reported acquired HIV drug resistance rate to be $6 \%$ while $3.7 \%$ rate for the transmitted HIV drug resistance [177]. The 2009 Surveillance Drug Resistance Mutation (SDRM) list has indicated 93 mutations including 34 NRTI-resistance mutations (at 15 RT positions), 19 NNRTI-resistance mutations (at $10 \mathrm{RT}$ positions), and $40 \mathrm{PI}$-resistance mutations (at 18 protease positions), and this suggests the vast number of mutations linked to antiretroviral drug resistance [178]. The fitness landscape of HIV-1 RT and protease has been shown to be under strong epistasis [179]. Epistasis refers to a situation wherein action of one genetic locus masks the allelic effects at another locus, and the locus thus masked is referred to be "hypostatic" to the other locus $[180,181]$. This phenomenon of epistatic interaction complicates comprehensive understanding of viral variants and their relationship to drug resistance. Even though today there are more than 20 different antiretroviral drugs to treat HIV-infected patients, a major global public health concern is the emergence of new strains that develop resistance to these drugs and subsequent transmission to other hosts [176].
Antiretroviral therapy has been quite successful which can be attributed to its ability to control HIV replication and preserve optimal $\mathrm{CD} 4^{+} \mathrm{T}$ helper cell population, due to which many of the opportunistic infections associated with abnormal low $\mathrm{CD}^{+}{ }^{+}$T-cell counts are averted. However, tuberculosis (TB), caused by Mycobacterium tuberculosis, can occur at any stage of the disease, irrespective of $\mathrm{CD} 4{ }^{+} \mathrm{T}$-cell counts, in HIV-1-infected patients [182] and poses a tremendous public health challenge in regions plagued by dual epidemic of HIV and TB. HIV-associated TB and hepatitis complicate the clinical management of individuals suffering from such coinfections, with potential for development of immune reconstitution inflammatory syndrome and drugdrug interactions are not clearly understood $[183,184]$.

HIV-1 latency presents challenges for the attempts directed at eradicating it. The half-life of the latent, replication-competent HIV-1 in resting $\mathrm{CD}^{+}{ }^{+} \mathrm{T}$ cells is roughly six months, which necessitates compliance to effective ART regimen for several years to clear the virus from reservoir [157]. Strategies are being contemplated to activate the HIV residing in latent reservoirs, in such a manner that does not allow wide-spread infection of uninfected cells $[185,186]$, and, in this regard, current and future ART drugs could play vital role in eradicating resilient virus.

\section{Conclusion}

The studies on biology of HIV-1 variation by characterizing emerging quasispecies population carries prognostic value as they impact rate of development of AIDS defining illnesses [187] as well as effectiveness of therapy [188]. Different recombinant forms of HIV-1 emerge, and they are seen to predominate in particular environments [189-191]. Given this scenario, more comprehensive epitope mapping studies with focus on CTL epitope escape mutants of CRFs, in addition to characterizing epitope profile of major HIV-1 clades, are warranted, and such findings will augment the efforts to curb spread of HIV-1, a virus nonpareil in medical history due to its ever elusive tricks inflicting damage to global health. The advent of HAART has made HIV/AIDS a lifethreatening fatal into a potential chronic disease. However, HIV patients under long-term treatment are likely to have higher risk for medical complications like heart, liver, and neurodegenerative diseases, and hence there is an increasing need to deal with these additional health issues effectively [192]. A vaccine that could elicit sterilizing immunity against HIV/AIDS is much desired. Recent findings, RV144 Trial, with its finding that prime-boost vaccine combination of ALVAC-HIV and AIDSVAX ${ }^{\circledR}$ B/E offering $39.2 \%$ protection against HIV [193]; a 1\% tenofovir gel inhibiting HIV sexual transmission by 39\% [194]; a person with 12 years of infection considered to be cured of HIV as part of fighting acute myeloid leukemia via haematopoietic stem cell transplantation from a CCR5 $\triangle 32$ homozygous donor [195-197] are quite encouraging and serve as testimonial to the fact that HIV-1 can be conquered through further research which includes dissecting mechanisms of underlying protection and moving forward with those anti-HIV immunobiological clues [198-201]. While debate on attenuation of HIV-1, as it 
evolves continues [36, 37, 202, 203], focused and concerted efforts by scientists, employing multidisciplinary approaches to attack HIV, might enable achieving UNAIDS mission of "zero new HIV infections, zero discrimination and zero AIDS-related deaths" earlier.

\section{Acknowledgment}

The authors convey thanks to anonymous reviewers for their valuable suggestions towards improving the paper.

\section{References}

[1] S. J. O’Brien and J. J. Goedert, "HIV causes AIDS: Koch's postulates fulfilled," Current Opinion in Immunology, vol. 8, no. 5, pp. 613-618, 1996.

[2] UNAIDS, "World AIDS day report 2011," Joint United Nations Programme on HIV/AIDS (UNAIDS), 2011.

[3] R. Marlink, R. Kanki, I. Thior et al., "Reduced rate of disease development after HIV-2 infection as compared to HIV-1," Science, vol. 265, no. 5178, pp. 1587-1590, 1994.

[4] L. Buonaguro, M. L. Tornesello, and F. M. Buonaguro, "Human immunodeficiency virus type 1 subtype distribution in the worldwide epidemic: pathogenetic and therapeutic implications," Journal of Virology, vol. 81, no. 19, pp. 10209-10219, 2007.

[5] P. M. Sharp and B. H. Hahn, "Origins of HIV and the AIDS Pandemic," Cold Spring Harbor Perspectives in Medicine, vol. 1, no. 1, Article ID a006841, 2011.

[6] E. Hooper, B. Korber, T. Bhattacharya et al., "Search for the origin of HIV and AIDS," Science, vol. 289, no. 5482, pp. 1140-1141, 2000.

[7] F. Simon, P. Mauclere, P. Roques et al., "Identification of a new human immunodeficiency virus type 1 distinct from group M and group O," Nature Medicine, vol. 4, no. 9, pp. 1032-1037, 1998.

[8] D. M. Tebit and E. J. Arts, "Tracking a century of global expansion and evolution of HIV to drive understanding and to combat disease," The Lancet Infectious Diseases, vol. 11, no. 1, pp. 45-56, 2011.

[9] J. C. Plantier, M. Leoz, J. E. Dickerson et al., "A new human immunodeficiency virus derived from gorillas," Nature Medicine, vol. 15, no. 8, pp. 871-872, 2009.

[10] A. Vallari, V. Holzmayer, B. Harris et al., "Confirmation of putative HIV-1 group P in Cameroon," Journal of Virology, vol. 85, no. 3, pp. 1403-1407, 2011.

[11] B. Korber, M. Muldoon, J. Theiler et al., "Timing the ancestor of the HIV-1 pandemic strains," Science, vol. 288, no. 5472, pp. 1789-1796, 2000.

[12] P. Lemey, O. G. Pybus, A. Rambaut et al., "The molecular population genetics of HIV-1 group O," Genetics, vol. 167, no. 3, pp. 1059-1068, 2004.

[13] J. O. Wertheim and M. Worobey, "Dating the age of the SIV lineages that gave rise to HIV-1 and HIV-2," PLoS Computational Biology, vol. 5, no. 5, Article ID e1000377, 2009.

[14] “HIV Databases," February 2012, http://www.hiv.lanl.gov/ content/sequence/HIV/mainpage.html.

[15] P. J. Kanki, D. J. Hamel, J. L. Sankale et al., "Human immunodeficiency virus type 1 subtypes differ in disease progression," Journal of Infectious Diseases, vol. 179, no. 1, pp. 68-73, 1999.
[16] B. G. Brenner, "Resistance and viral subtypes: how important are the differences and why do they occur?" Current Opinion in HIV and AIDS, vol. 2, no. 2, pp. 94-102, 2007.

[17] A. Vasan, B. Renjifo, E. Hertzmark et al., "Different rates of disease progression of HIV type 1 infection in Tanzania based on infecting subtype," Clinical Infectious Diseases, vol. 42, no. 6, pp. 843-852, 2006.

[18] A. Abraha, I. L. Nankya, R. Gibson et al., "CCR5- and CXCR4-tropic subtype $\mathrm{C}$ human immunodeficiency virus type 1 isolates have a lower level of pathogenic fitness than other dominant group M subtypes: implications for the epidemic," Journal of Virology, vol. 83, no. 11, pp. 5592-5602, 2009.

[19] J. E. Cummins Jr., W. J. Bunn, S. D. Hall, H. H. Donze, J. Mestecky, and S. Jackson, "In Vitro exposure to highly cytopathic HIV-1 X4 strains increases expression of mucosa-associated integrins on CD4+ T Cells," Virology, vol. 280, no. 2, pp. 262-272, 2001.

[20] G. A. Funk, A. Oxenius, M. Fischer et al., "HIV replication elicits little cytopathic effects in vivo: analysis of surrogate markers for virus production, cytotoxic $\mathrm{T}$ cell response and infected cell death," Journal of Medical Virology, vol. 78, no. 9, pp. 1141-1146, 2006.

[21] M. Peeters, R. Vincent, J. L. Perret et al., "Evidence for differences in MT2 cell tropism according to genetic subtypes of HIV-1: syncytium-inducing variants seem rare among subtype C HIV-1 viruses," Journal of Acquired Immune Deficiency Syndromes and Human Retrovirology, vol. 20, no. 2, pp. 115-121, 1999.

[22] C. Tscherning, A. Alaeus, R. Fredriksson et al., "Differences in chemokine coreceptor usage between genetic subtypes of HIV-1," Virology, vol. 241, no. 2, pp. 181-188, 1998.

[23] M. H. Naghavi, S. Schwartz, A. Sönnerborg, and A. Vahlne, "Long terminal repeat promoter/enhancer activity of different subtypes of HIV type 1," AIDS Research and Human Retroviruses, vol. 15, no. 14, pp. 1293-1303, 1999.

[24] R. E. Jeeninga, M. Hoogenkamp, M. Armand-Ugon, M. De Baar, K. Verhoef, and B. Berkhout, "Functional differences between the long terminal repeat transcriptional promoters of human immunodeficiency virus type 1 subtypes A through G," Journal of Virology, vol. 74, no. 8, pp. 3740-3751, 2000.

[25] M. A. Montano, C. P. Nixon, T. Ndung'u et al., "Elevated tumor necrosis factor- $\alpha$ activation of human immunodeficiency virus type 1 subtype $\mathrm{C}$ in southern Africa is associated with an NF- $\kappa$ B enhancer gain-of-function," Journal of Infectious Diseases, vol. 181, no. 1, pp. 76-81, 2000.

[26] F. Gao, D. L. Robertson, C. D. Carruthers et al., "A comprehensive panel of near-full-length clones and reference sequences for non-subtype B isolates of human immunodeficiency virus type 1," Journal of Virology, vol. 72, no. 7, pp. 5680-5698, 1998.

[27] L. V. Wain, E. Bailes, F. Bibollet-Ruche et al., "Adaptation of HIV-1 to Its Human Host," Molecular Biology and Evolution, vol. 24, no. 8, pp. 1853-1860, 2007.

[28] E. Domingo, E. Baranowski, C. M. Ruiz-Jarabo, A. M. Martin-Hernandez, J. C. Saiz, and C. Escarmis, "Quasispecies structure and persistence of RNA viruses," Emerging Infectious Diseases, vol. 4, no. 4, pp. 521-527, 1998.

[29] A. S. Lauring and R. Andino, "Quasispecies theory and the behavior of RNA viruses," PLoS Pathogens, vol. 6, no. 7, Article ID e1001005, 2010. 
[30] J. Ji and L. A. Loeb, "Fidelity of HIV-1 reverse transcriptase copying RNA in vitro," Biochemistry, vol. 31, no. 4, pp. 954958, 1992.

[31] V. K. Pathak and W. S. Hu, “"Might as well jump!” template switching by retroviral reverse transcriptase, defective genome formation, and recombination," Seminars in Virology, vol. 8, no. 2, pp. 141-150, 1997.

[32] B. F. Keele, E. E. Giorgi, J. F. Salazar-Gonzalez et al., "Identification and characterization of transmitted and early founder virus envelopes in primary HIV-1 infection," Proceedings of the National Academy of Sciences of the United States of America, vol. 105, no. 21, pp. 7552-7557, 2008.

[33] M. R. Abrahams, J. A. Anderson, E. E. Giorgi et al., "Quantitating the multiplicity of infection with human immunodeficiency virus type 1 subtype $\mathrm{C}$ reveals a non-poisson distribution of transmitted variants," Journal of Virology, vol. 83, no. 8, pp. 3556-3567, 2009.

[34] W. Fischer, V. V. Ganusov, E. E. Giorgi et al., "Transmission of single HIV-1 genomes and dynamics of early immune escape revealed by ultra-deep sequencing," PLoS One, vol. 5, no. 8, Article ID e12303, 2010.

[35] B. Gaschen, C. Kuiken, B. Korber, and B. Foley, "Retrieval and on-the-fly alignment of sequence fragments from the HIV database," Bioinformatics, vol. 17, no. 5, pp. 415-418, 2001.

[36] J. T. Herbeck, G. S. Gottlieb, X. Li et al., "Lack of evidence for changing virulence of HIV-1 in North America," PLoS One, vol. 3, no. 2, Article ID e1525, 2008.

[37] N. Crum-Cianflone, L. Eberly, Y. Zhang et al., "Is HIV becoming more virulent? Initial CD4 cell counts among HIV seroconverters during the course of the HIV epidemic: 19852007," Clinical Infectious Diseases, vol. 48, no. 9, pp. 12851292, 2009.

[38] J. D. Altman and M. B. Feinberg, "HIV escape: there and back again,” Nature Medicine, vol. 10, no. 3, pp. 229-230, 2004.

[39] S. Alizon, V. von Wyl, T. Stadler et al., "Phylogenetic approach reveals that virus genotype largely determines HIV set-point viral load," PLoS Pathogens, vol. 6, no. 9, Article ID e01123, 2010.

[40] F. D. Bushman, C. Hoffmann, K. Ronen et al., "Massively parallel pyrosequencing in HIV research," AIDS, vol. 22, no. 12, pp. 1411-1415, 2008.

[41] “454 Sequencing, GS FLX+ System, Roche," December 2011, http://my454.com/downloads/GSFLXApplicationFlyer_FINAL v2.pdf.

[42] C. S. Pareek, R. Smoczynski, and A. Tretyn, "Sequencing technologies and genome sequencing," Journal of Applied Genetics, vol. 52, no. 4, pp. 413-435, 2011.

[43] A. M. N. Tsibris, B. Korber, R. Arnaout et al., "Quantitative deep sequencing reveals dynamic HIV-1 escape and large population shifts during CCR5 antagonist therapy in vivo," PLoS One, vol. 4, no. 5, Article ID e5683, 2009.

[44] B. Liang, M. Luo, J. Scott-Herridge et al., "A comparison of parallel pyrosequencing and sanger clone-based sequencing and its impact on the characterization of the genetic diversity of HIV-1," PLoS One, vol. 6, no. 10, Article ID e26745, 2011.

[45] S. Palmer, M. Kearney, F. Maldarelli et al., "Multiple, linked human immunodeficiency virus type 1 drug resistance mutations in treatment-experienced patients are missed by standard genotype analysis," Journal of Clinical Microbiology, vol. 43, no. 1, pp. 406-413, 2005.

[46] J. Zhang, "Host RNA polymerase II makes minimal contributions to retroviral frame-shift mutations," Journal of General Virology, vol. 85, no. 8, pp. 2389-2395, 2004.
[47] A. C. van der Kuyl and M. Cornelissen, "Identifying HIV-1 dual infections," Retrovirology, vol. 4, article no. 67, 2007.

[48] A. R. Templeton, M. G. Kramer, J. Jarvis et al., "Multipleinfection and recombination in HIV-1 within a longitudinal cohort of women," Retrovirology, vol. 6, article no. 54, 2009.

[49] D. Shriner, A. G. Rodrigo, D. C. Nickle, and J. I. Mullins, "Pervasive genomic recombination of HIV-1 in vivo," Genetics, vol. 167, no. 4, pp. 1573-1583, 2004.

[50] N. N. V. Vijay, Vasantika, R. Ajmani, A. S. Perelson, and N. M. Dixit, "Recombination increases human immunodeficiency virus fitness, but not necessarily diversity," Journal of General Virology, vol. 89, no. 6, pp. 1467-1477, 2008.

[51] A. M. Land, T. B. Ball, M. Luo et al., "Full-length HIV type 1 proviral sequencing of 10 highly exposed women from Nairobi, Kenya reveals a high proportion of intersubtype recombinants," AIDS Research and Human Retroviruses, vol. 24, no. 6, pp. 865-872, 2008.

[52] A. M. Land, M. Luo, R. Pilon et al., "High prevalence of genetically similar HIV-1 recombinants among infected sex workers in Nairobi, Kenya," AIDS Research and Human Retroviruses, vol. 24, no. 11, pp. 1455-1460, 2008.

[53] K. Delviks-Frankenberry, A. Galli, O. Nikolaitchik, H. Mens, V. K. Pathak, and W. S. Hu, "Mechanisms and factors that influence high frequency retroviral recombination," Viruses, vol. 3, no. 9, pp. 1650-1680, 2011.

[54] K. Motomura, J. Chen, and W. S. Hu, "Genetic recombination between human immunodeficiency virus type 1 (HIV1) and HIV-2, two distinct human lentiviruses," Journal of Virology, vol. 82, no. 4, pp. 1923-1933, 2008.

[55] B. Ramratnam, S. Bonhoeffer, J. Binley et al., "Rapid production and clearance of HIV-1 and hepatitis $\mathrm{C}$ virus assessed by large volume plasma apheresis," Lancet, vol. 354, no. 9192, pp. 1782-1785, 1999.

[56] L. M. Mansky and L. C. Bernard, “3'-Azido-3'-deoxythymidine (AZT) and AZT-resistant reverse transcriptase can increase the in vivo mutation rate of human immunodeficiency virus type 1," Journal of Virology, vol. 74, no. 20, pp. 9532-9539, 2000.

[57] J. Martinez-Picado and M. A. Martínez, "HIV-1 reverse transcriptase inhibitor resistance mutations and fitness: a view from the clinic and ex vivo," Virus Research, vol. 134, no. 1-2, pp. 104-123, 2008.

[58] J. M. Coffin, "HIV population dynamics in vivo: implications for genetic variation, pathogenesis, and therapy," Science, vol. 267, no. 5197, pp. 483-489, 1995.

[59] K. J. Metzner, S. Bonhoeffer, M. Fischer et al., "Emergence of minor populations of human immunodeficiency virus type 1 carrying the M184V and L90M mutations in subjects undergoing structured treatment interruptions," Journal of Infectious Diseases, vol. 188, no. 10, pp. 1433-1443, 2003.

[60] “Stanford HIV Drug Resistance Database," February 2012, http://hivdb.stanford.edu.

[61] J. Fellay, K. V. Shianna, D. Ge et al., "A whole-genome association study of major determinants for host control of HIV1," Science, vol. 317, no. 5840, pp. 944-947, 2007.

[62] J. Klein and A. Sato, "The HLA system: first of two parts," New England Journal of Medicine, vol. 343, no. 10, pp. 702709, 2000.

[63] K. J. M. Jeffery and C. R. M. Bangham, "Do infectious diseases drive MHC diversity?" Microbes and Infection, vol. 2, no. 11, pp. 1335-1341, 2000.

[64] M. Carrington and S. J. O'Brien, “The Influence of HLA Genotype on AIDS," Annual Review of Medicine, vol. 54, pp. 535-551, 2003. 
[65] H. A. F. Stephens, "HIV-1 diversity versus HLA class I polymorphism," Trends in Immunology, vol. 26, no. 1, pp. 4147, 2005.

[66] C. M. Rousseau, M. G. Daniels, J. M. Carlson et al., "HLA class I-driven evolution of human immunodeficiency virus type 1 subtype C proteome: immune escape and viral load," Journal of Virology, vol. 82, no. 13, pp. 6434-6446, 2008.

[67] Y. Kawashima, K. Pfafferott, J. Frater et al., "Adaptation of HIV-1 to human leukocyte antigen class I," Nature, vol. 458, no. 7238, pp. 641-645, 2009.

[68] Y. Zhang, Y. Peng, H. Yan et al., "Multilayered defense in HLA-B51-associated HIV viral control," Journal of Immunology, vol. 187, no. 2, pp. 684-691, 2011.

[69] J. N. Blankson, J. R. Bailey, and R. F. Siliciano, "Crosscurrents in HIV-1 evolution," Nature Immunology, vol. 7, no. 2, pp. 121-122, 2006.

[70] B. Liang, M. Luo, T. B. Ball, and F. A. Plummer, "QUASI analysis of the HIV-1 envelope sequences in the Los Alamos National Laboratory HIV sequence database: pattern and distribution of positive selection sites and their frequencies over years," Biochemistry and Cell Biology, vol. 85, no. 2, pp. 259-264, 2007.

[71] H. O. Peters, M. G. Mendoza, R. E. Capina et al., "An integrative bioinformatic approach for studying escape mutations in human immunodeficiency virus type 1 gag in the Pumwani sex worker cohort," Journal of Virology, vol. 82, no. 4, pp. 1980-1992, 2008.

[72] B. Liang, M. Luo, T. B. Ball et al., "Systematic analysis of host immunological pressure on the envelope gene of human immunodeficiency virus type 1 by an immunobioinformatics approach," Current HIV Research, vol. 6, no. 4, pp. 370-379, 2008.

[73] C. A. Semeniuk, L. McKinnon, H. O. Peters et al., "Multiple T-cell epitopes overlap positively-selected residues in the $\mathrm{p} 1$ spacer protein of HIV-1 gag," AIDS, vol. 23, no. 7, pp. 771777, 2009.

[74] B. Liang, M. Luo, T. B. Ball, S. J. M. Jones, and F. A. Plummer, "QUASI analysis of host immune responses to Gag polyproteins of human immunodeficiency virus type 1 by a systematic bioinformatics approach," Biochemistry and Cell Biology, vol. 88, no. 4, pp. 671-681, 2010.

[75] J. Snoeck, J. Fellay, I. Bartha, D. C. Douek, and A. Telenti, "Mapping of positive selection sites in the HIV-1 genome in the context of RNA and protein structural constraints," Retrovirology, vol. 8, no. 1, article 87, 2011.

[76] H. Barroso and N. Taveira, "Evidence for negative selective pressure in HIV-2 evolution in vivo," Infection, Genetics and Evolution, vol. 5, no. 3, pp. 239-246, 2005.

[77] S. J. O'Brien and G. W. Nelson, "Human genes that limit AIDS,” Nature Genetics, vol. 36, no. 6, pp. 565-574, 2004.

[78] P. An and C. A. Winkler, "Host genes associated with HIV/ AIDS: advances in gene discovery," Trends in Genetics, vol. 26, no. 3, pp. 119-131, 2010.

[79] S. Neil and P. Bieniasz, "Human immunodeficiency virus, restriction factors, and interferon," Journal of Interferon and Cytokine Research, vol. 29, no. 9, pp. 569-580, 2009.

[80] A. M. Land, T. B. Ball, M. Luo et al., "Human immunodeficiency virus (HIV) type 1 proviral hypermutation correlates with CD4 count in HIV-infected women from Kenya," Journal of Virology, vol. 82, no. 16, pp. 8172-8182, 2008.

[81] R. S. Harris and M. T. Liddament, "Retroviral restriction by APOBEC proteins," Nature Reviews Immunology, vol. 4, no. 11, pp. 868-877, 2004.
[82] P. Jern, R. A. Russell, V. K. Pathak, and J. M. Coffin, "Likely role of APOBEC3G-mediated G-to-A mutations in HIV-1 evolution and drug resistance," PLoS Pathogens, vol. 5, no. 4, Article ID e1000367, 2009.

[83] S. Fourati, I. Malet, M. Binka et al., "Partially active HIV-1 Vif alleles facilitate viral escape from specific antiretrovirals," AIDS, vol. 24, no. 15, pp. 2313-2321, 2010.

[84] N. Wood, T. Bhattacharya, B. F. Keele et al., "HIV evolution in early infection: selection pressures, patterns of insertion and deletion, and the impact of APOBEC," PLoS Pathogens, vol. 5, no. 5, Article ID e1000414, 2009.

[85] E. Y. Kim, T. Bhattacharya, K. Kunstman et al., "Human APOBEC3G-mediated editing can promote HIV-1 sequence diversification and accelerate adaptation to selective pressure," Journal of Virology, vol. 84, no. 19, pp. 10402-10405, 2010.

[86] H. A. Sadler, M. D. Stenglein, R. S. Harris, and L. M. Mansky, "APOBEC3G contributes to HIV-1 variation through sublethal mutagenesis," Journal of Virology, vol. 84, no. 14, pp. 7396-7404, 2010.

[87] L. C. F. Mulder, A. Harari, and V. Simon, "Cytidine deamination induced HIV-1 drug resistance," Proceedings of the National Academy of Sciences of the United States of America, vol. 105, no. 14, pp. 5501-5506, 2008.

[88] J. M. Norman, M. Mashiba, L. A. McNamara et al., "The antiviral factor APOBEC3G enhances the recognition of HIV-infected primary T cells by natural killer cells," Nature Immunology, vol. 12, no. 10, pp. 975-983, 2011.

[89] N. Van Damme, D. Goff, C. Katsura et al., "The interferoninduced protein BST-2 restricts HIV-1 release and is downregulated from the cell surface by the viral Vpu protein," Cell Host and Microbe, vol. 3, no. 4, pp. 245-252, 2008.

[90] S. J. Yang, L. A. Lopez, C. M. Exline, K. G. Haworth, and P. M. Cannon, "Lack of adaptation to human tetherin in HIV-1 group O and P," Retrovirology, vol. 8, article 78, 2011.

[91] L. Liu, N. M. Oliveira, K. M. Cheney et al., "A whole genome screen for HIV restriction factors," Retrovirology, vol. 8, article 94, 2011.

[92] A. Telenti, "HIV-1 host interactions: integration of largescale datasets," F1000 Biology Reports, vol. 1, article 71, 2009.

[93] N. Goonetilleke, M. K. P. Liu, J. F. Salazar-Gonzalez et al., "The first T cell response to transmitted/founder virus contributes to the control of acute viremia in HIV-1 infection," Journal of Experimental Medicine, vol. 206, no. 6, pp. 12531272, 2009.

[94] J. Da Silva and A. L. Hughes, "Conservation of cytotoxic T lymphocyte (CTL) epitopes as a host strategy to constrain parasite adaptation: evidence from the nef gene of human immunodeficiency virus 1 (HIV-1)," Molecular Biology and Evolution, vol. 15, no. 10, pp. 1259-1268, 1998.

[95] A. J. Leslie, K. J. Pfafferott, P. Chetty et al., "HIV evolution: CTL escape mutation and reversion after transmission," Nature Medicine, vol. 10, no. 3, pp. 282-289, 2004.

[96] M. Altfeld, M. M. Addo, E. S. Rosenberg et al., "Influence of HLA-B57 on clinical presentation and viral control during acute HIV-1 infection," AIDS, vol. 17, no. 18, pp. 2581-2591, 2003.

[97] M. Rotger, J. Dalmau, A. Rauch et al., "Comparative transcriptomics of extreme phenotypes of human HIV-1 infection and SIV infection in sooty mangabey and rhesus macaque," Journal of Clinical Investigation, vol. 121, no. 6, pp. 23912400, 2011.

[98] H. N. Kloverpris, A. Stryhn, M. Harndahl et al., "HLA-B*57 Micropolymorphism shapes HLA allele-specific epitope 
immunogenicity, selection pressure, and HIV immune control," Journal of Virology, vol. 86, no. 2, pp. 919-929, 2012.

[99] T. Dong, Y. Zhang, K. Y. Xu et al., "Extensive HLA-driven viral diversity following a narrow-source HIV-1 outbreak in rural China," Blood, vol. 118, no. 1, pp. 98-106, 2011.

[100] International HIVCS, F. Pereyra, X. Jia et al., "The major genetic determinants of HIV-1 control affect HLA class I peptide presentation," Science, vol. 330, no. 6010, pp. 15511557, 2010.

[101] P. Kiepiela, A. J. Leslie, I. Honeyborne et al., "Dominant influence of HLA-B in mediating the potential co-evolution of HIV and HLA," Nature, vol. 432, no. 7018, pp. 769-774, 2004.

[102] A. I. Fontaine Costa, X. Rao, E. Lechenadec, D. Van Baarle, and C. Keşmir, "HLA-B molecules target more conserved regions of the HIV-1 proteome," AIDS, vol. 24, no. 2, pp. 211-215, 2010.

[103] M. Ciccozzi, I. Bon, and M. Ciotti, "Do the HIV-1 subtypes circulating in Italy resemble the Red Queen running in Carroll's novel?" New Microbiologica, vol. 33, no. 2, pp. 179_ $181,2010$.

[104] M. Luo, J. Kimani, N. J. Nagelkerke et al., "Rapid selection for HLA alleles that protect against HIV-1 infection correlates significantly to the declining incidence of HIV-1 in an East African sex worker population," in 16th Annual Canadian Conference on HIV/AIDS Research (CAHR '07), Toronto, Canada, April 2007.

[105] A. A. Bashirova, R. Thomas, and M. Carrington, "HLA/KIR restraint of HIV: surviving the fittest," Annual Review of Immunology, vol. 29, pp. 295-317, 2011.

[106] E. Battivelli, J. Migraine, D. Lecossier, P. Yeni, F. Clavel, and A. J. Hance, "Gag cytotoxic T lymphocyte escape mutations can increase sensitivity of HIV-1 to human TRIM5alpha, linking intrinsic and acquired immunity," Journal of Virology, vol. 85, no. 22, pp. 11846-11854, 2011.

[107] O. O. Yang, J. Church, C. M. R. Kitchen et al., "Genetic and stochastic influences on the interaction of human immunodeficiency virus type 1 and cytotoxic T lymphocytes in identical twins," Journal of Virology, vol. 79, no. 24, pp. 15368$15375,2005$.

[108] R. Draenert, T. M. Allen, Y. Liu et al., "Constraints on HIV-1 evolution and immunodominance revealed in monozygotic adult twins infected with the same virus," Journal of Experimental Medicine, vol. 203, no. 3, pp. 529-539, 2006.

[109] D. H. O'Connor and D. R. Burton, "Immune responses and HIV: a little order from the chaos," Journal of Experimental Medicine, vol. 203, no. 3, pp. 501-503, 2006.

[110] V. Dahirel, K. Shekhar, F. Pereyra et al., "Coordinate linkage of HIV evolution reveals regions of immunological vulnerability," Proceedings of the National Academy of Sciences of the United States of America, vol. 108, no. 28, pp. 11530-11535, 2011.

[111] J. J. Just, "Genetic predisposition to HIV-1 infection and acquired immune deficiency virus syndrome: a review of the literature examining associations with HLA," Human Immunology, vol. 44, no. 3, pp. 156-169, 1995.

[112] A. T. Makadzange, G. Gillespie, T. Dong et al., "Characterization of an HLA-C-restricted CTL response in chronic HIV infection," European Journal of Immunology, vol. 40, no. 4, pp. 1036-1041, 2010.

[113] J. K. Wright, Z. L. Brumme, B. Julg et al., "Lack of association between HLA class II alleles and in vitro replication capacities of recombinant viruses encoding HIV-1 subtype C Gagprotease from chronically infected individuals," Journal of Virology, vol. 86, no. 2, pp. 1273-1276, 2012.
[114] G. C. Harcourt, S. Garrard, M. P. Davenport, A. Edwards, and R. E. Phillips, "HIV-1 variation diminishes CD4 T lymphocyte recognition," Journal of Experimental Medicine, vol. 188, no. 10, pp. 1785-1793, 1998.

[115] G. Ahlenstiel, K. Roomp, M. Däumer et al., "Selective pressures of HLA genotypes and antiviral therapy on human immunodeficiency virus type 1 sequence mutation at a population level," Clinical and Vaccine Immunology, vol. 14, no. 10, pp. 1266-1273, 2007.

[116] R. A. Hardie, E. Knight, B. Bruneau et al., "A common human leucocyte antigen-DP genotype is associated with resistance to HIV-1 infection in Kenyan sex workers," AIDS, vol. 22, no. 15, pp. 2038-2042, 2008.

[117] R. A. Hardie, M. Luo, B. Bruneau et al., "Human leukocyte antigen-DQ alleles and haplotypes and their associations with resistance and susceptibility to HIV-1 infection," AIDS, vol. 22, no. 7, pp. 807-816, 2008.

[118] P. A. Lacap, J. D. Huntington, M. Luo et al., "Associations of human leukocyte antigen DRB with resistance or susceptibility to HIV-1 infection in the Pumwani Sex Worker Cohort," AIDS, vol. 22, no. 9, pp. 1029-1038, 2008.

[119] S. Raghavan, K. Alagarasu, and P. Selvaraj, "Immunogenetics of HIV and HIV associated tuberculosis," Tuberculosis (Edinb), vol. 92, no. 1, pp. 18-30, 2012.

[120] B. Julg, E. S. Moodley, Y. Qi et al., "Possession of HLA class II DRB1*1303 associates with reduced viral loads in chronic HIV-1 clade C and B infection," Journal of Infectious Diseases, vol. 203, no. 6, pp. 803-809, 2011.

[121] B. T. Korber, N. L. Letvin, and B. F. Haynes, "T-cell vaccine strategies for human immunodeficiency virus, the virus with a thousand faces," Journal of Virology, vol. 83, no. 17, pp. 8300-8314, 2009.

[122] L. R. McKinnon, R. Kaul, M. Herman, F. A. Plummer, and T. B. Ball, "HIV-specific T cells: strategies for fighting a moving target," Current HIV Research, vol. 8, no. 8, pp. 587-595, 2010.

[123] S. Kulkarni, M. P. Martin, and M. Carrington, "The Yin and Yang of HLA and KIR in human disease," Seminars in Immunology, vol. 20, no. 6, pp. 343-352, 2008.

[124] K. M. Jamil and S. I. Khakoo, "KIR/HLA interactions and pathogen immunity," Journal of Biomedicine and Biotechnology, vol. 2011, Article ID 298348, 9 pages, 2011.

[125] G. B. Cohen, R. T. Gandhi, D. M. Davis et al., "The selective downregulation of class I major histocompatibility complex proteins by HIV-1 protects HIV-infected cells from NK cells," Immunity, vol. 10, no. 6, pp. 661-671, 1999.

[126] S. Gaudieri, D. DeSantis, E. McKinnon et al., "Killer immunoglobulin-like receptors and HLA act both independently and synergistically to modify HIV disease progression," Genes and Immunity, vol. 6, no. 8, pp. 683-690, 2005.

[127] M. P. Martin, Y. Qi, X. Gao et al., "Innate partnership of HLAB and KIR3DL1 subtypes against HIV-1," Nature Genetics, vol. 39, no. 6, pp. 733-740, 2007.

[128] K. Pelak, A. C. Need, J. Fellay et al., "Copy number variation of KIR genes influences HIV-1 control,” PLoS Biology, vol. 9, no. 11, Article ID e1001208, 2011.

[129] G. Alter, D. Heckerman, A. Schneidewind et al., "HIV-1 adaptation to NK-cell-mediated immune pressure," Nature, vol. 476, no. 7358, pp. 96-100, 2011.

[130] G. B. Karlsson Hedestam, R. A. M. Fouchier, S. Phogat, D. R. Burton, J. Sodroski, and R. T. Wyatt, "The challenges of eliciting neutralizing antibodies to HIV-1 and to influenza virus," Nature Reviews Microbiology, vol. 6, no. 2, pp. 143155, 2008. 
[131] L. Stamatatos, L. Morris, D. R. Burton, and J. R. Mascola, "Neutralizing antibodies generated during natural HIV-1 infection: good news for an HIV-1 vaccine?" Nature medicine, vol. 15, no. 8, pp. 866-870, 2009.

[132] M. J. McElrath and B. F. Haynes, "Induction of immunity to human immunodeficiency virus type-1 by vaccination," Immunity, vol. 33, no. 4, pp. 542-554, 2010.

[133] J. Cohen, "AIDS research. Novel antibody response may explain HIV vaccine success," Science, vol. 333, no. 6049, p. 1560, 2011.

[134] D. D. Richman, T. Wrin, S. J. Little, and C. J. Petropoulos, "Rapid evolution of the neutralizing antibody response to HIV type 1 infection," Proceedings of the National Academy of Sciences of the United States of America, vol. 100, no. 7, pp. 4144-4149, 2003.

[135] X. Wei, J. M. Decker, S. Wang et al., "Antibody neutralization and escape by HIV-1," Nature, vol. 422, no. 6929, pp. 307312, 2003.

[136] X. Wu, Z. Y. Yang, Y. Li et al., "Rational design of envelope identifies broadly neutralizing human monoclonal antibodies to HIV-1," Science, vol. 329, no. 5993, pp. 856-861, 2010.

[137] X. Wu, T. Zhou, J. Zhu et al., "Focused evolution of HIV1 neutralizing antibodies revealed by structures and deep sequencing," Science, vol. 333, no. 6049, pp. 1593-1602, 2011.

[138] J. F. Scheid, H. Mouquet, B. Ueberheide et al., "Sequence and structural convergence of broad and potent HIV antibodies that mimic CD4 binding," Science, vol. 333, no. 6049, pp. 1633-1637, 2011.

[139] A. Rauch, D. Nolan, H. Furrer et al., "HLA-Bw4 homozygosity is associated with an impaired CD4 T cell recovery after initiation of antiretroviral therapy," Clinical Infectious Diseases, vol. 46, no. 12, pp. 1921-1925, 2008.

[140] M. H. Kuniholm, X. Gao, X. Xue et al., "Human leukocyte antigen genotype and risk of HIV disease progression before and after initiation of antiretroviral therapy," Journal of Virology, vol. 85, no. 20, pp. 10826-10833, 2011.

[141] M. Koga, A. Kawana-Tachikawa, D. Heckerman et al., "Changes in impact of HLA class I allele expression on HIV-1 plasma virus loads at a population level over time," Microbiology and Immunology, vol. 54, no. 4, pp. 196-205, 2010.

[142] J. K. Carr, "Viral diversity as a challenge to HIV-1 vaccine development," Current Opinion in HIV and AIDS, vol. 1, no. 4, pp. 294-300, 2006.

[143] W. A. Burgers, A. Manrique, D. Masopust et al., "Measurements of immune responses for establishing correlates of vaccine protection against HIV," AIDS Research and Human Retroviruses. In press.

[144] M. P. Davenport, R. M. Ribeiro, D. L. Chao, and A. S. Perelson, "Predicting the impact of a nonsterilizing vaccine against human immunodeficiency virus," Journal of Virology, vol. 78, no. 20, pp. 11340-11351, 2004.

[145] S. K. Lakhashe, G. Silvestri, and R. M. Ruprecht, "No acquisition: a new ambition for HIV vaccine development?" Current Opinion in Virology, vol. 1, no. 4, pp. 246-253, 2011.

[146] F. A. Plummer, T. B. Ball, J. Kimani, and K. R. Fowke, "Resistance to HIV-1 infection among highly exposed sex workers in Nairobi: what mediates protection and why does it develop?" Immunology Letters, vol. 66, no. 1-3, pp. 27-34, 1999.

[147] L. Piacentini, C. Fenizia, V. Naddeo, and M. Clerici, "Not just sheer luck! Immune correlates of protection against HIV-1 infection," Vaccine, vol. 26, no. 24, pp. 3002-3007, 2008.

[148] J. N. Blankson, "Effector mechanisms in HIV-1 infected elite controllers: highly active immune responses?" Antiviral Research, vol. 85, no. 1, pp. 295-302, 2010.
[149] A. Burgener, J. Sainsbury, F. A. Plummer, and T. Blake Ball, "Systems biology-based approaches to understand HIVexposed uninfected women," Current HIV/AIDS Reports, vol. 7, no. 2, pp. 53-59, 2010.

[150] B. Autran, B. Descours, V. Avettand-Fenoel, and C. Rouzioux, "Elite controllers as a model of functional cure," Current Opinion in HIV and AIDS, vol. 6, no. 3, pp. 181-187, 2011.

[151] J. M. Young, J. A. Turpin, R. Musib, and O. K. Sharma, "Outcomes of a national institute of allergy and infectious diseases workshop on understanding HIV-exposed but seronegative individuals," AIDS Research and Human Retroviruses, vol. 27, no. 7, pp. 737-743, 2011.

[152] L. M. Luft, M. J. Gill, and D. L. Church, "HIV-1 viral diversity and its implications for viral load testing: review of current platforms," International Journal of Infectious Diseases, vol. 15, no. 10, pp. e661-e670, 2011.

[153] M. S. Cohen, Y. Q. Chen, M. McCauley et al., "Prevention of HIV-1 infection with early antiretroviral therapy," New England Journal of Medicine, vol. 365, no. 6, pp. 493-505, 2011.

[154] C. Deleage, M. Moreau, N. Rioux-Leclercq, A. Ruffault, B. Jegou, and N. Dejucq-Rainsford, "Human immunodeficiency virus infects human seminal vesicles in vitro and in vivo," The American Journal of Pathology, vol. 179, no. 5, pp. 2397-2408, 2011.

[155] V. Cobos-Jiménez, T. Booiman, J. Hamann, and N. A. Kootstra, "Macrophages and HIV-1," Current Opinion in HIV and AIDS, vol. 6, no. 5, pp. 385-390, 2011.

[156] J. K. Wong, M. Hezareh, H. F. Günthard et al., "Recovery of replication-competent HIV despite prolonged suppression of plasma viremia," Science, vol. 278, no. 5341, pp. 1291-1295, 1997.

[157] L. Zhang, B. Ramratnam, K. Tenner-Racz et al., "Quantifying residual HIV-1 replication in patients receiving combination antiretroviral therapy," New England Journal of Medicine, vol. 340, no. 21, pp. 1605-1613, 1999.

[158] J. Stebbing, B. Gazzard, and D. C. Douek, "Where does HIV live?” The New England journal of medicine, vol. 350, no. 18, pp. 1872-1880, 2004.

[159] S. K. Choudhary and D. M. Margolis, "Curing HIV: pharmacologic approaches to target HIV-1 Latency," Annual Review of Pharmacology and Toxicology, vol. 51, pp. 397-418, 2011.

[160] E. H. Gisolf, R. H. Enting, S. Jurriaans et al., "Cerebrospinal fluid HIV-1 RNA during treatment with ritonavir/saquinavir or ritonavir/saquinavir/stavudine," AIDS, vol. 14, no. 11, pp. 1583-1589, 2000.

[161] C. Solas, A. Lafeuillade, P. Halfon, S. Chadapaud, G. Hittinger, and B. Lacarelle, "Discrepancies between protease inhibitor concentrations and viral load in reservoirs and sanctuary sites in human immunodeficiency virus-infected patients," Antimicrobial Agents and Chemotherapy, vol. 47, no. 1, pp. 238-243, 2003.

[162] K. M. McGrath, N. G. Hoffman, W. Resch, J. A. E. Nelson, and R. Swanstrom, "Using HIV-1 sequence variability to explore virus biology," Virus Research, vol. 76, no. 2, pp. 137$160,2001$.

[163] J. J. Eron, P. L. Vernazza, D. M. Johnston et al., "Resistance of HIV-1 to antiretroviral agents in blood and seminal plasma: implications for transmission," AIDS, vol. 12, no. 15, pp. F181-F189, 1998.

[164] R. W. Coombs, C. E. Speck, J. P. Hughes et al., "Association between culturable human immunodeficiency virus type 1 (HIV- 1) in semen and HIV-1 RNA levels in semen and blood: evidence for compartmentalization of HIV-1 between 
semen and blood," Journal of Infectious Diseases, vol. 177, no. 2, pp. 320-330, 1998.

[165] L. H. Ping, M. S. Cohen, I. Hoffman et al., "Effects of genital tract inflammation on human immunodeficiency virus type 1 V3 populations in blood and semen," Journal of Virology, vol. 74, no. 19, pp. 8946-8952, 2000.

[166] G. Venturi, M. Catucci, L. Romano et al., "Antiretroviral resistance mutations in human immunodeficiency virus type 1 reverse transcriptase and protease from paired cerebrospinal fluid and plasma samples," Journal of Infectious Diseases, vol. 181, no. 2, pp. 740-745, 2000.

[167] Y. Quan, B. G. Brenner, A. Dascal, and M. A. Wainberg, "Highly diversified multiply drug-resistant HIV-1 quasispecies in PBMCs: a case report," Retrovirology, vol. 5, article no. 43, 2008.

[168] P. R. Harrigan, M. Whaley, and J. S. G. Montaner, "Rate of HIV-1 RNA rebound upon stopping antiretroviral therapy," AIDS, vol. 13, no. 8, pp. F59-F62, 1999.

[169] J. Z. Li, R. Paredes, H. J. Ribaudo et al., "Low-frequency HIV-1 drug resistance mutations and risk of NNRTI-based antiretroviral treatment failure: a systematic review and pooled analysis," Journal of the American Medical Association, vol. 305, no. 13, pp. 1327-1335, 2011.

[170] V. Jain, M. C. Sucupira, P. Bacchetti et al., "Differential persistence of transmitted HIV-1 drug resistance mutation classes," Journal of Infectious Diseases, vol. 203, no. 8, pp. 1174-1181, 2011.

[171] M. Saag, R. Balu, E. Phillips et al., "High sensitivity of human leukocyte antigen-B*5701 as a marker for immunologically confirmed abacavir hypersensitivity in white and black patients," Clinical Infectious Diseases, vol. 46, no. 7, pp. 11111118, 2008.

[172] M. Chaponda and M. Pirmohamed, "Hypersensitivity reactions to HIV therapy," British Journal of Clinical Pharmacology, vol. 71, no. 5, pp. 659-671, 2011.

[173] A. R. Hughes, W. R. Spreen, M. Mosteller et al., "Pharmacogenetics of hypersensitivity to abacavir: from PGx hypothesis to confirmation to clinical utility," Pharmacogenomics Journal, vol. 8, no. 6, pp. 365-374, 2008.

[174] M. He, Y. H. Zheng, H. Y. Zhou et al., "Prospective observation for seven-year's highly active antiretroviral therapy in Chinese HIV-1 infected patients," Current HIV Research, vol. 9, no. 3, pp. 160-165, 2011.

[175] G. Hirnschall and B. Schwartländer, "Treatment 2.0: catalysing the next phase of scale-up." Lancet, vol. 378, no. 9787, pp. 209-211, 2011.

[176] WHO, "Antiretroviral therapy for HIV infection in adults and adolescents: recommendations for a public health approach," 2010.

[177] WHO, "HIV Drug resistance fact sheet," April 2011, http:// www.who.int/hiv/facts/drug_resistance/en/index.html.

[178] D. E. Bennett, R. J. Camacho, D. Otelea et al., "Drug resistance mutations for surveillance of transmitted HIV-1 drugresistance: 2009 update," PLoS One, vol. 4, no. 3, Article ID e4724, 2009.

[179] T. Hinkley, J. Martins, C. Chappey et al., "A systems analysis of mutational effects in HIV-1 protease and reverse transcriptase," Nature Genetics, vol. 43, no. 5, pp. 487-489, 2011.

[180] O. Carlborg and C. S. Haley, "Epistasis: too often neglected in complex trait studies?" Nature Reviews Genetics, vol. 5, no. 8, pp. 618-625, 2004.

[181] P. C. Phillips, "The language of gene interaction," Genetics, vol. 149 , no. 3, pp. 1167-1171, 1998.
[182] S. Swaminathan, R. Ramachandran, G. Baskaran et al., "Risk of development of tuberculosis in HIV-infected patients," International Journal of Tuberculosis and Lung Disease, vol. 4, no. 9, pp. 839-844, 2000.

[183] K. K. Venkatesh, S. Swaminathan, J. R. Andrews, and K. H. Mayer, "Tuberculosis and HIV co-infection: screening and treatment strategies," Drugs, vol. 71, no. 9, pp. 1133-1152, 2011.

[184] M. Jones and M. Nunez, "HIV and hepatitis C co-infection: the role of HAART in HIV/hepatitis C virus management," Current Opinion in HIV and AIDS, vol. 6, no. 6, pp. 546-552, 2011.

[185] R. F. Siliciano and W. C. Greene, "HIV latency," Cold Spring Harbor Perspectives in Medicine, vol. 1, Article ID a007096, 2011.

[186] J. Cohen, "Understanding HIV latency to undo it," Science, vol. 332, no. 6031, p. 786, 2011.

[187] S. Ganeshan, R. E. Dickover, B. T. M. Korber, Y. J. Bryson, and S. M. Wolinsky, "Human immunodeficiency virus type 1 genetic evolution in children with different rates of development of disease," Journal of Virology, vol. 71, no. 1, pp. 663677, 1997.

[188] K. Metzner, "The significance of minority drug-resistant quasispecies," in Antiretroviral Resistance in Clinical Practice, A. M. Geretti, Ed., Mediscript, London, UK, 2006.

[189] C. M. Rousseau, G. H. Learn, T. Bhattacharya et al., "Extensive intrasubtype recombination in South African human immunodeficiency virus type 1 subtype C infections," Journal of Virology, vol. 81, no. 9, pp. 4492-4500, 2007.

[190] P. C. Aulicino, E. C. Holmes, C. Rocco, A. Mangano, and L. Sen, "Extremely rapid spread of human immunodeficiency virus type 1 BF recombinants in Argentina," Journal of Virology, vol. 81, no. 1, pp. 427-429, 2007.

[191] P. Frange, J. Galimand, N. Vidal et al., "New and old complex recombinant HIV-1 strains among patients with primary infection in 1996-2006 in France: the French ANRS CO06 primo cohort study," Retrovirology, vol. 5, article no. 69, 2008.

[192] P. A. Volberding and S. G. Deeks, "Antiretroviral therapy and management of HIV infection," The Lancet, vol. 376, no. 9734, pp. 49-62, 2010.

[193] S. Rerks-Ngarm, P. Pitisuttithum, S. Nitayaphan et al., "Vaccination with ALVAC and AIDSVAX to prevent HIV-1 infection in Thailand," New England Journal of Medicine, vol. 361, no. 23, pp. 2209-2220, 2009.

[194] Q. A. Karim, S. S. A. Karim, J. A. Frohlich et al., "Effectiveness and safety of tenofovir gel, an antiretroviral microbicide, for the prevention of HIV infection in women," Science, vol. 329, no. 5996, pp. 1168-1174, 2010.

[195] K. Allers, G. Hütter, J. Hofmann et al., "Evidence for the cure of HIV infection by CCR $5 \Delta 32 / \Delta 32$ stem cell transplantation," Blood, vol. 117, no. 10, pp. 2791-2799, 2011.

[196] G. Hutter and S. Ganepola, "Eradication of HIV by transplantation of CCR5-deficient hematopoietic stem cells," TheScientificWorldJournal, vol. 11, pp. 1068-1076, 2011.

[197] G. Hütter and E. Thiel, "Allogeneic transplantation of CCR5deficient progenitor cells in a patient with HIV infection: an update after 3 years and the search for patient no. 2," AIDS, vol. 25, no. 2, pp. 273-274, 2011.

[198] L. R. McKinnon and C. M. Card, "HIV vaccine efficacy trials: a brief history, and options for going forward," AIDS Reviews, vol. 12, no. 4, pp. 209-217, 2010.

[199] C. W. Dieffenbach and A. S. Fauci, "Thirty years of HIV and AIDS: future challenges and opportunities," Annals of Internal Medicine, vol. 154, no. 11, pp. 766-771, 2011. 
[200] L. J. Picker, S. G. Hansen, and J. D. Lifson, "New paradigms for HIV/AIDS vaccine development," Annual Review of Medicine, vol. 63, pp. 95-111, 2012.

[201] J. Cohen, "The emerging race to cure HIV infections," Science, vol. 332, no. 6031, pp. 784-789, 2011.

[202] Y. Gali, B. Berkhout, G. Vanham, M. Bakker, N. K. T. Back, and K. K. Ariën, "Survey of the temporal changes in HIV-1 replicative fitness in the Amsterdam Cohort," Virology, vol. 364, no. 1, pp. 140-146, 2007.

[203] K. K. Arien, G. Vanham, and E. J. Arts, "Is HIV-1 evolving to a less virulent form in humans?" Nature Reviews Microbiology, vol. 5, no. 2, pp. 141-151, 2007. 

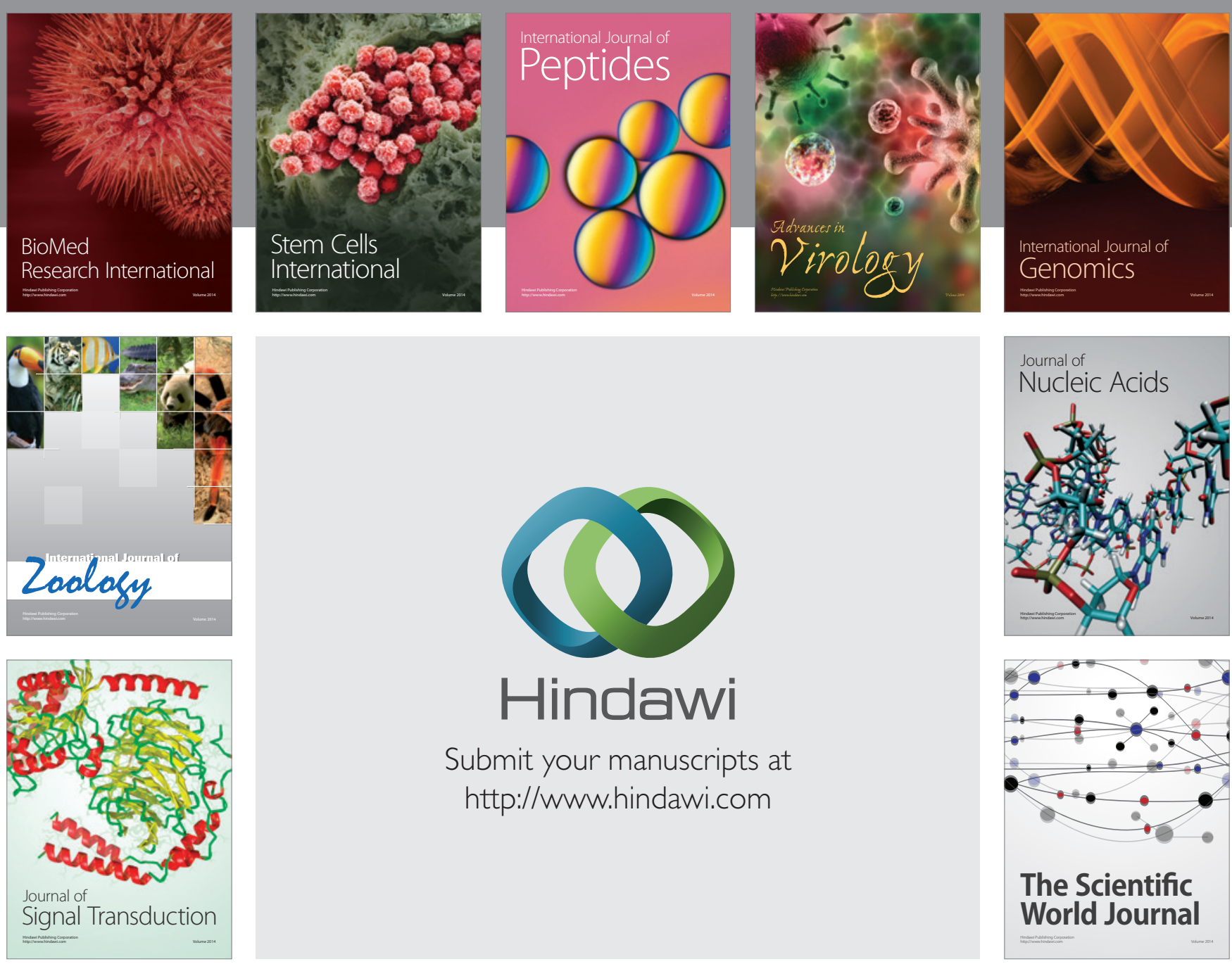

Submit your manuscripts at

http://www.hindawi.com
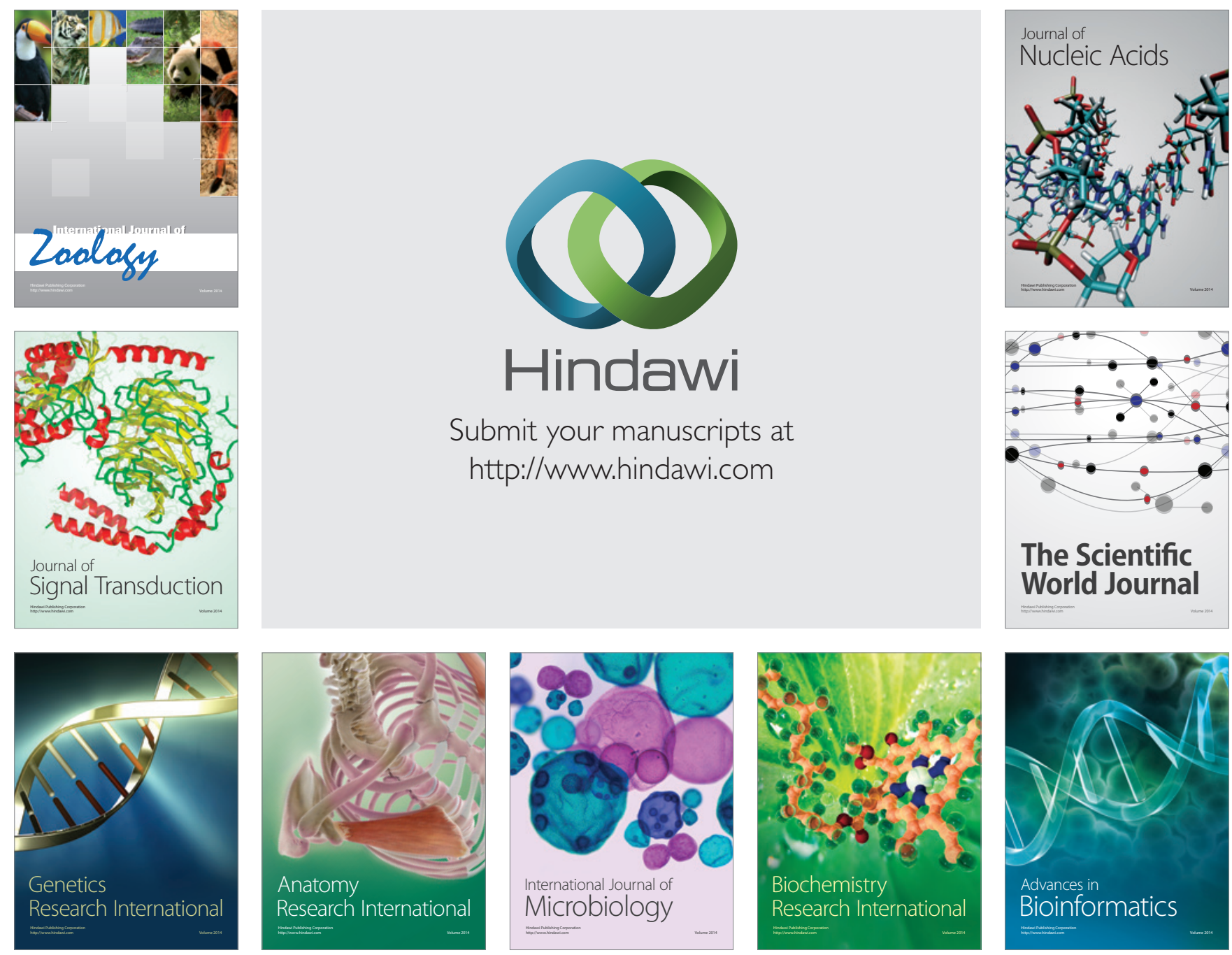

The Scientific World Journal
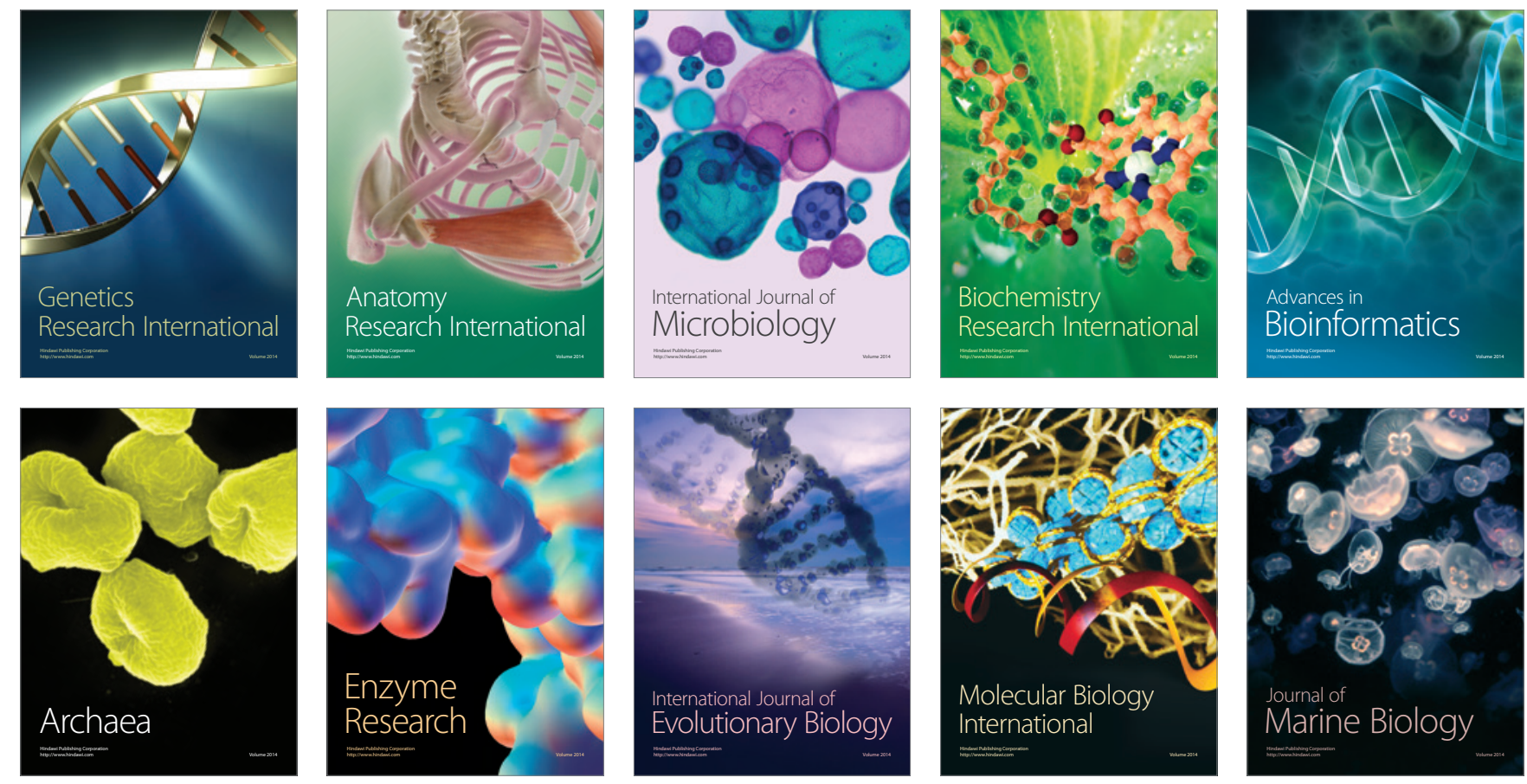